\title{
The intraday determination of liquidity in the NYSE LIFFE equity option markets*
}

\author{
Thanos Verousis ${ }^{\dagger}$ \\ School of Management, University of Bath, Bath, BA2 7AY, UK \\ Owain ap Gwilym \\ Bangor Business School, Bangor University, Bangor, LL57 2DG, UK. \\ XiaoHua Chen \\ School of Management, University of Bath, Bath, BA2 7AY, UK
}

\begin{abstract}
We exploit an extensive high frequency dataset of all individual equity options trading at NYSE LIFFE (Amsterdam, London and Paris) in order to study the determination of liquidity during the trading day. In particular, we focus on two main aspects of option liquidity: (i) the intraday behaviour of equity option liquidity and its determinants and (ii) the influence of macro-economic events and commonality on intraday equity option liquidity. Inventory management models cannot explain the intraday variation in option spreads and depths. Instead, we show that the option liquidity measures are strongly correlated with option volatility. Increases in volatility are associated with decreases in liquidity, a finding that is in line with information asymmetry models and the derivatives hedging theory. However, the relationship between spreads and volume varies across the three markets. Option liquidity reacts strongly to macroeconomic news announcements, especially US events. The average systematic liquidity component is $12 \%$ for Amsterdam, $14 \%$ for London and $16 \%$ for Paris.
\end{abstract}

Keywords: LIFFE, options, liquidity, bid-ask spread, depth JEL: G12, G19

\footnotetext{
* We are grateful to conference participants at the 2013 Forecasting Financial Markets conference, Ania Zalewska, Simone Giansante and especially the two anonymous referees for valuable comments and suggestions.

† Corresponding author: +44 (0) 1225 386314, t.verousis@bath.ac.uk
} 


\section{Introduction}

The events of the financial crisis have highlighted the importance of understanding liquidity in financial markets. In equity markets, there is an extensive body of literature that investigates the microstructure of asset liquidity. ${ }^{1}$ However, for option markets, the literature on liquidity is very thin and to our knowledge there are no studies on the intraday determination of equity option liquidity. ${ }^{2}$ For the US options market, Wei and Zheng (2010) show that option volatility is the most important determinant of daily option liquidity, and Cao and Wei (2010) document strong liquidity commonality in daily data, even after controlling for the impact of the underlying market.

In this paper, we seek to address a gap in the literature on equity option liquidity by providing an intraday analysis of an extensive high frequency dataset of all individual equity options trading at NYSE LIFFE Amsterdam, London and Paris. In particular, we focus on two main aspects of option liquidity: (i) the intraday behaviour of equity option liquidity and its determinants and (ii) the influence of macro-economic events and commonality on intraday equity option liquidity.

Regarding the first aspect of the paper, we initially examine the extent to which inventory management models can explain the intraday behaviour of liquidity in the equity options market. Importantly, while several studies present evidence of the intraday behaviour of

\footnotetext{
${ }^{1}$ Several recent market microstructure studies investigate liquidity determination in the order book (Danielsson and Payne, 2012), the effect of the introduction of the electronic order book on liquidity (Gregoriou, forthcoming), commonality in liquidity (Dunne et al., 2011), liquidity and market making (Montalvo, 2003) and hidden liquidity (Pardo and Pascual, 2012).

${ }^{2}$ Earlier literature on the intraday patterns of equity option liquidity includes Chan, Christie and Schultz (1995), Chan, Chung and Johnson (1995) and George and Longstaff (1993).
} 
liquidity measures in settings with specialist market makers, the only previous study on both spreads and depths for a competitive dealer market is by Frino et al. (2008) for the Sydney Futures Exchange (SFE). These authors show that, in the context of changing financial market structures, more evidence is needed in order to conclude that inventories are driving trading costs in the setting of a competitive dealer market. We contribute new and different evidence to this debate. In contrast to Frino et al. (2008), we demonstrate that inventory management models cannot explain the intraday variation in option spreads and depths. We further study the determinants of intraday equity option liquidity, and show that the option liquidity measures are strongly correlated with option volatility. In contrast to the expected outcome if inventory risk were an important component of the bid-ask spread, increases in volume and volatility at the Amsterdam market are generally associated with decreases in liquidity. These findings are in line with information asymmetry models. However, for London and Paris, we find evidence to support both the information asymmetry and inventory management models.

Relating to the sources of option liquidity, the literature is silent on the effect of macroeconomic news announcements on intraday option liquidity. ${ }^{3}$ Further, we use Principal Component Analysis (PCA) to identify the intraday pattern of systematic liquidity that may drive this relationship. We provide evidence that option liquidity reacts strongly to macroeconomic news announcements that are related to country-specific, European and US events. The average systematic liquidity component is $12 \%$ for Amsterdam, $14 \%$ for London and $16 \%$ for Paris. Systematic liquidity varies considerably during the trading day and is at its

\footnotetext{
${ }^{3}$ In this respect, our study relates to the FX literature on intraday news announcements (see Dominguez and Panthaki, 2006).
} 
highest level during the market open, levels off during the day but has two distinctive peaks at 13:30 and 15:00.

With regard to the different aspects of liquidity discussed above, we contribute to the literature in a number of ways. This is the first paper to use such a comprehensive dataset of quotes and trades to study individual equity option liquidity. Our findings imply a clear need for richer models of intraday volatility to incorporate liquidity spill-over effects. Also, the extent to which equity option spreads are affected by macroeconomic news announcements delivers new insights on the intraday determination of option liquidity and the systematic component of liquidity.

The remainder of the paper is organised as follows. Section 2 outlines the market structure of NYSE LIFFE and Section 3 discusses the development of hypotheses. Section 4 outlines the data selection and variable construction. Section 5 discusses the empirical results and the final section concludes the paper.

\section{NYSE LIFFE Market Structure}

NYSE LIFFE is the European derivatives branch of NYSE, overseeing a total of five European markets (Amsterdam, Brussels, Lisbon, London and Paris). Trading in individual equity options occurs on the Amsterdam, Brussels, London and Paris exchanges. ${ }^{4}$ Trading on NYSE LIFFE occurs via LIFFE CONNECT, an anonymous, electronic, order-driven system, which operates an "open system" architecture allowing users direct access via an Application Program Interface (API). ${ }^{5}$ Market makers act as liquidity providers on NYSE LIFFE under

\footnotetext{
${ }^{4}$ Brussels is dropped from the analysis due to limited trading.

5 "How the Euronext.liffe markets work". Available on the NYSE LIFFE website.
} 
the Euronext Liquidity Provider System (ELPS), which was originally introduced for the Amsterdam options market and has since migrated to all individual equity contracts traded on LIFFE CONNECT. Market making refers to the simultaneous submission of bid and ask quotations that meet the spread and size obligations set by the scheme for each particular contract.

With the exception of Amsterdam, NYSE LIFFE uses two terms for market makers in these markets. Primary Liquidity Providers (PLP) provide continuous quotes for a number of inthe-money and out-of-the-money contracts. Competitive Liquidity Providers (CLP) provide continuous quotes for a number of near-the-money contracts. ${ }^{6}$ For NYSE LIFFE Amsterdam, Competitive Market Makers (CMM) have obligations similar to CLPs and Primary Market Makers (PMM) provide continuous quotes across all series in all maturities for all individual equity options (further details below). Market makers effectively submit limit orders for which time and price priority rules also apply and in return receive trading fee rebates which are determined by the liquidity provider's performance based on meeting the minimum quotation requirements. ${ }^{7}$

Market makers' spread and size obligations are a function of the price and volatility of the underlying asset (updated semi-annually) and refer to maximum spread and minimum size (e.g. a maximum spread of 50p and a minimum of 10 contracts). Spread and size obligations are therefore not uniform across all assets. Market makers are obliged to offer continuous quotes for at least $85 \%$ of the relevant number of series and during at least $85 \%$ of the

\footnotetext{
6 "Near-the-money" is a dynamic area and is defined as a percentage mark up (down) from the lowest (highest) underlying share price of the current day.

${ }^{7}$ PMMs may also have the right to receive a percentage of the turnover traded at the PMM's best bid or ask price. CMMs and PMMs may quote spreads up to twice the maximum contractually agreed spread.
} 
specific time period. All market makers are required to trade a minimum number of contracts of high liquidity assets. ${ }^{8}$ Trading fee reductions are not uniform and are based on monthly evaluations of each market maker's performance.

The above arrangements provide a degree of discretion to market makers regarding meeting their spread and size obligations. This implies that the minimum level of liquidity is not always achieved and this is further reinforced by the fact that market participants cannot submit quote requests to market makers. Market makers as well as non-market makers are able to view the complete depth of the order book, depending on their trading arrangements with the exchange. In Chan, Chung and Johnson's (1995) dataset, the order book was separately handled by an exchange employee, depriving the market makers from the information contained within it (see Vijh, 1990). A crucial difference between our work and Chan, Chung and Johnson (1995) is the fact that the order book is a major component in our study (see Neal, 1992). ${ }^{9}$ This feature of NYSE LIFFE considerably reduces the role of inventory risk management for option contracts. The exchange is responsible for allocating market makers for each individual equity option, however during the period that the schemes run, several market maker mutations occur and new market makers may be added on specific tickers. ${ }^{10}$

\footnotetext{
${ }^{8}$ Asset liquidity and hence the number of market makers for each asset is assessed and defined by the exchange.

${ }^{9}$ At NYSE LIFFE, market makers' trades are indistinguishable from limit order book trades i.e. market makers are obliged to post quotes at the limit order book whereas at CBOE market makers did not trade on the order book. In contrast, Chung and Zhao (2004) show that spreads established by market makers on NYSE stocks reflect market making costs which are however distinguishable from the spreads established on the limit order book.

${ }^{10}$ Unfortunately, the exchange does not publish any market making statistics, especially with regard to the overall proportion of trading that is conducted via market makers. However, the exchange has confirmed to the
} 


\section{Development of Hypotheses}

\subsection{Models of intraday equity option liquidity and its determinants}

The first hypothesis is concerned with the role of market makers in the determination of intraday equity option liquidity in the context of a hybrid order book market with competing market makers. Section 2 describes the process of market making at NYSE LIFFE and here we draw attention to the intraday pattern of equity option liquidity and the determinants of intraday option liquidity.

A popular explanation for the intraday determination of liquidity is the inventory management theory (see Ho and Stoll, 1981; Amihud and Mendelson, 1982). This theory argues that market makers have a "preferred" inventory level and hence there is a cost involved in any deviation. Market makers adjust their bid-ask prices to optimize their inventory levels, thus bid-ask spreads widen when their inventory level diverges from the 'preferred' level.

Alternative explanations focus on the role of information in the determination of intraday liquidity. In particular, the information asymmetry hypothesis posits that investors will adjust their spreads when the probability of trading with an informed trader increases (see Ho and Stoll, 1983; Glosten and Milgrom, 1985; Kyle, 1985). Empirical evidence provides support for this hypothesis. Charoenwong and Chung (2000) show that specialists and limit order traders quote smaller depths for riskier stocks (defined by high return volatility) to limit potential losses to informed traders, and quote larger depths for stocks with greater trading volume. For the US options market, Wei and Zheng (2010) show that option volatility is the most important determinant of daily option liquidity. Wyart et al. (2008) identify a strong

authors that the Amsterdam market is dominated by non-market makers, whereas the London and Paris markets rely more on the market-making facility. 
positive correlation between spread and the volatility per trade (i.e., mid-point return volatility), implying that the main determinant of the bid-ask spread is the adverse selection component arising from informed trading. Chordia et al. (2001) document that volatility is closely associated with asymmetric information and that higher volatility leads to wider spreads in equity markets. Finally, Danielsson and Payne (2012) show that intraday liquidity is strongly positively associated with intraday volatility in the FX market.

In a similar context, Cho and Engle (2009) and Engle and Neri (2010) argue that the positive association between option spreads and option liquidity can be explained by the derivatives hedging theory. The latter implies that option market makers are mainly concerned with hedging their positions in the underlying market. Hence, as long as their option trades are hedged, the inventory management component of the spread is no longer a significant option liquidity determinant.

We hypothesize that in a "decentralized" trading system such as the equity options market at NYSE LIFFE, the influence of inventory management practices on option liquidity is diminished. The latter is in line with the predictions of Ho and Stoll (1983) for a competitive dealer market. Therefore, we propose the following hypothesis.

Hypothesis 1: In an order book market with competing market makers, traders are more concerned with option volatility than inventory management.

Further, to date, there are no empirical studies on the intraday determinants of equity option liquidity. We develop hypotheses based on relevant studies for the US options market (see Wei and Zheng, 2010) and drawing from empirical findings for the equity and FX markets. For the FX market, Danielsson and Payne (2012) show that spreads widen and depths are reduced in high volume and volatile intraday intervals. For the equity markets, volatility is 
closely associated with asymmetric information and higher volatility leads to wider spreads (see Chordia et al., 2001).

Also, for the US options market, Wei and Zheng (2010) argue that an inverse relationship between spreads and volume is expected if inventory risk is important. Similarly, Engle and Neri (2010) predict the same relationship because higher volume implies lower order processing costs.

Transaction frequency also reflects order processing costs and spreads are expected to widen when the number of trades decreases. Cho and Engle (1999) hypothesize that the expected relationship between bid-ask spread and time-to-maturity is negative because American-style options that are near maturity are more likely to be exercised and this will increase the difficulty for market makers to maintain their hedged positions. Wei and Zheng (2010) show that moneyness reflects the leverage effect or the effect of option return volatility. Dufour and Engle (2000) show that spreads are positively correlated with trade duration. Based on the above we develop the following hypothesis:

Hypothesis 2: Intraday equity option liquidity is positively related to volatility and trade duration and negatively related to volume, trade frequency, maturity and moneyness.

\subsection{Macro-economic news and equity option liquidity}

A topic which is closely related to the determinants of equity option liquidity is the incorporation of information in asset prices. That is, how is liquidity determined following the arrival of new macroeconomic information? A number of previous studies address this issue for equity and bond markets (e.g. Chordia et al., 2001 and Riordan et al., 2013), however there are no studies on this question in the equity options market. Fleming and Remolona (1999) find that the arrival of macroeconomic announcements in the U.S. Treasury 
market sets off a two-stage adjustment process for intraday bid-ask spreads, trading volume and prices, where spreads widen in a brief first stage and remain moderately wide (the normal level) in a prolonged second stage. The authors explain that market makers widen (or withdraw) their bid and ask quotes in response to the inventory risks of sharp price changes at an announcement time, then the sharp price change is followed by a surge in trading volume that narrows the spread. Fleming and Krishnan (2012) find a similar pattern in the U.S. Treasury inflation-protected securities market. Since theory and empirical literature suggest that macroeconomic news affects asset prices and liquidity, we conjecture that option market liquidity will also react significantly to these events.

Hypothesis 3: Intraday equity option liquidity deteriorates immediately following a macroeconomic news event but reverts quickly to "normal" levels.

\subsection{Commonality in intraday equity option liquidity}

The proposition that equity option liquidity at NYSE LIFFE is affected by macroeconomic news also implies that there could be a strong systematic component in the liquidity. This systematic liquidity would capture the market-wide effects during a trading day. Huberman and Halka (2001) document the presence of a systematic, time-varying component of liquidity in NYSE stocks using daily data. Chordia et al. (2000) and Hasbrouck and Seppi (2001) find an intraday common component in US stock liquidity. Using a high-frequency dataset on Greek stocks, Dunne et al. (2011) document substantial co-movements in returns, order flows and liquidity, both on a market-wide basis and on an individual security basis. Based on these empirical findings in stock markets, we conjecture the similar existence of systematic liquidity in the option market. 
Hypothesis 4: Intraday equity option liquidity exhibits strong commonality during the trading day.

\section{Data, Empirical Specification and Descriptive Statistics}

\subsection{Data sources and sample selection}

We use an extensive intraday dataset consisting of 34 months of tick data for all individual equity options (henceforth tickers) trading at NYSE-LIFFE Amsterdam, London and Paris, from March 2008 to December 2010. ${ }^{11}$ The option contracts traded for each ticker vary according to strike price, maturity date and contract type (i.e. call or put) (these are referred to as 'sub-tickers' hereafter). The data files contain information on maturity date, strike price, volume and price, time-stamped to the nearest second, separately for asks, bids and trades. We omit tickers for which we failed to identify their underlying instruments from DataStream. For Paris, we omit European-style contracts so that all options in the sample are American-style. For Amsterdam, we omit options traded on weekly and daily expiry cycles, because there are few of these contracts and their short expiry cycles may distort the results. Overall, the majority of tickers remain in the sample (see Panel A of Table 1). For Amsterdam, 90 percent of contracts are retained, while the figures for London (Paris) are 93 (84) percent.

\footnotetext{
***insert Table 1 here***
}

\footnotetext{
${ }^{11}$ The number of tickers reflects the total number of firm-options trading at the exchanges and includes delisted options.
} 
For each exchange and contract type (call or put), we categorize sub-tickers according to their moneyness level and days to expiration. Moneyness is defined as $\mathrm{S} / \mathrm{K}$, where $\mathrm{S}$ refers to the daily opening price of the underlying asset (not adjusted for dividend payments) and $\mathrm{K}$ refers to the option strike price. We subsequently select sub-tickers that fall within the at-the-money range (defined here as 0.95 to 1.05). Similarly, we control for expiration effects by focusing on short-term options only; sub-tickers that are between 90 and 7 days from expiration are selected.

We delete outliers based on spread and price criteria as follows. All zero volume, zero price and out-of-hours observations are deleted. ${ }^{12}$ Quotes with negative or zero bid-ask spreads are dropped from the sample. Also, as in Wei and Zheng (2010), we control for possible outlying data by dropping quotes with excessively large bid-ask spreads. The cut-off point for the percentage bid-ask spreads is set at $150 \%$.

\subsection{Estimation of liquidity variables}

We estimate several variables. Quoted spreads and depth serve as estimates of quote liquidity. Intraday volatility is based on 5-minute absolute returns. Traded volume and transaction frequency are derived from the trades sample and time-to-maturity and moneyness are allocated to each intraday interval. All variables are estimated at a ticker level

\footnotetext{
${ }^{12}$ All three exchanges are open between 08:00 and 16:30 (London time). We drop the first five and last five minutes of trading from the calculations in order to avoid any overnight effects on prices and price distortions during the last five minutes of trading. We also delete half-days. There are no zero-volume trades in the raw dataset. However we include this restriction because the sample contains reported trades hence all trades should contain a reported traded volume. The latter is an important distinction from datasets where market orders may contain zero volume (pre-reporting).
} 
and then aggregated to equal-weighted averages for each date-time interval. The definitions of each variable are described below.

The estimation of quoted spreads, depths and option returns is based on sub-ticker midquotes which are calculated at 5-minute intervals from bid and ask prices as follows. At each trading day, we select the first quote of the day which is however quoted no later than 8.01am. We then retain bid and ask quotes at 5-minute intervals, h, however we control for stale pricing by dropping bid and ask prices that are recorded more than two minutes prior to each 5minute interval. For the closing return (16:30), a 2-minute rule applies. We only estimate midquotes when both ask and bid prices are found within the aforementioned intervals. The above procedure allows us to maintain the maximum number of observations at regular time intervals, controlling at the same time for the biases of missing variables and stale pricing. The above discussion does not imply that the 5-minute spreads are calculated from one bid and one ask price only. Instead, we calculate the average per sub-tickers for all quotes that meet the criteria within each time interval. Excluding the opening and closing, $n$ denotes the total number of intraday intervals (101).

The most commonly used spread measure is the quoted bid-ask spread, defined as the difference between the most recent ask and bid prices (see Petrella, 2006; Cao and Wei, 2010; Wei and Zheng, 2010). For each sub-ticker, we control for price level differences by calculating the percentage bid-ask spread $\left(P B A S_{t}\right)$, defined as the ratio of quoted spread over the quote midpoint:

$$
P B A S_{5-\min }=100 \times \frac{A s k_{5-\min }-B_{i d_{5-\min }}}{M_{5-\min }}
$$


where $A_{s k_{5-\min }}$ and $B_{i d_{5-\min }}$ are the ask and bid prices sampled at 5-minute intervals respectively and and $M_{5-\min }$ is the trade midquote defined as half the sum of bid and ask prices at each interval. A reciprocal measure of liquidity is quoted depth (see Harris, 1990). Lee et al. (1993) show that spreads are only one dimension of liquidity, because dealers who narrow spreads while reducing depths may be perceived as providing more liquidity while in fact they do not. They conclude that decreases (increases) in liquidity are associated with a simultaneous widening (narrowing) of the spread and a reduction (increase) in depth. Vijh (1990) associates depth with the number of market makers because increases in the number of market makers are associated with higher costs of carrying more inventory. The author shows that market depth at the $\mathrm{CBOE}$ is offered at the expense of wider bid-ask spreads, thus when depths increase, spreads also widen because market makers request higher compensation to recover the higher inventory costs of providing greater depth. These results are opposite to those reported by Lee et al. (1993) for the NYSE whereby depths and spreads are inversely related, reflecting two dimensions of liquidity. ${ }^{13}$ In an order-book setting, spreads and depths are expected to be substitutes if greater depths have no implication for inventory management costs.

We measure quoted depth (Depth) in number of contracts as follows:

$$
\text { Depth }_{5-\min }=\frac{\text { Volume }_{a s k, 5-\min }+\text { Volume }_{\text {bid }, 5-\min }}{2}
$$

\footnotetext{
${ }^{13}$ It can be shown that liquidity has four dimensions: width, depth, immediacy, resiliency (see Cho and Engle, 1999). Width (spread) and depth are by far the most common liquidity measures. On NYSE LIFFE, spread and depth are combined to define the contractual obligations of liquidity providers.
} 
where Volume ask,5-min $_{\text {and }}$ Volume Bid,5-min refer to the number of contracts quoted at the ask and bid prices, respectively.

Logarithmic intraday returns $(r)$ are calculated on midquote prices at a sub-ticker level, however large jumps may be recorded (despite the maximum spread selection criterion). Also, a problem arises with the calculation of realized volatility in less liquid markets as the definition of realized volatility (sum of intraday squared returns) implies that returns are estimated for all intraday intervals. We alleviate these issues as follows. First, we omit returns whose absolute value is greater than three standard deviations from their mean per ticker (only one percent of the observations). Returns are averaged for each ticker at an intraday level. Second, we use the absolute value of intraday 5-minute returns as a measure of intraday volatility. Finally, in order to be consistent with the use of quoted liquidity and to avoid any stale pricing problems, we use the average quoted volume per interval as an intraday measure of trading activity. We construct equally-weighted averages at each interval for all variables and each intraday variable is standardized by subtracting the daily mean and dividing by the daily standard deviation for each trading day of each ticker.

\subsection{Descriptive statistics}

Panel B of Table 1 presents the descriptive statistics, separately for each market and also for calls and puts. For Amsterdam, the average percentage spread is 12.18 percent for calls and 11.41 percent for puts. For London, spreads are on average 18.20 percent for calls and 16.78 for puts and for Paris the equivalent figures are 13.90 and 12.78 respectively. We reject the null hypotheses of an equality of means across calls and puts for each market. 
The depth value for Amsterdam is substantially greater than those for London and Paris, which is somewhat surprising as further analysis shows that the actual trade size in Amsterdam differs little from the actual trade sizes in other LIFFE markets. The explanation lies in the differences in the composition of investors across markets. A 2011 survey by NYSE Euronext and TNS Sofres found that equity option contracts are particularly popular among retail investors in Amsterdam, whereas retail investors in Paris are much less likely to participate in option markets. Specifically, 62 percent of the survey respondents held options in the Netherlands compared to 5 percent in France. The exchange has confirmed that retail trading activity in London is also much lower than in Amsterdam. Discussions with market makers have revealed that it is standard practice to quote large depths in the Amsterdam market as a means to reassure retail investors that the market is sufficiently liquid. Under these circumstances, a sudden drop in depth in Amsterdam may not imply a drop in liquidity.

Across all three markets, put prices are less volatile than call prices and we uniformly reject the null hypothesis of equality in the distribution between calls and puts. The average traded volume for each five minute interval is 266.44 (209.30) for calls (puts) in Amsterdam. For London (Paris), the corresponding figures are 35.31 (98.26) for puts and 39.92 (110.79) for calls.Both London and Paris report on average less than one trade per interval whereas in Amsterdam transaction frequency increases substantially to an average 8 trades per interval for calls and 6 for puts. ${ }^{14}$ The difference in traded liquidity is also reflected in the duration between trades. The average duration is 14 (18) minutes for Amsterdam calls (puts), 44 (49) minutes for London calls (puts), and 39 (43) minutes for Paris calls (puts).

\footnotetext{
${ }^{14}$ In this table, transaction frequency refers to the ratio of the total number of trades per category over the total number of date-time intervals.
} 
Table 2 presents the average option quoted bid-ask spreads within volatility, volume and transaction frequency quintiles. Spreads widen with higher levels of option volatility. This finding holds for each market and for both calls and puts. Also, depths decrease with option volatility. Option volume is associated with option volatility, and according to the inventory management theory, spreads should narrow with option volume (see Wei and Zheng, 2010). In contrast to this inventory management theory, spreads widen with volume in each market. Mixed results are reported for depths for London and Paris. Clearly, depth decreases for Amsterdam. Finally, transaction frequency is generally considered a measure of order processing costs. For all three markets, spreads widen with higher levels of transaction frequency. Also, for Amsterdam and London, depths motonotically increase with transaction frequency, but this finding is not confirmed for Paris. The Kruskal-Wallis test statistics for equality of means of each quintile across market and contract types uniformly reject the null hypothesis. Table 2 offers preliminary evidence relating to Hypothesis 1 .

\section{Empirical Analysis}

\subsection{Intraday behaviour of equity option liquidity and its determinants}

In the first part of this sub-section, we examine to what extent inventory management can explain the intraday behaviour of liquidity in the equity options market (Hypothesis 1). As discussed in Section 3, we hypothesize that in a "decentralized" trading system like NYSE LIFFE for equity options, inventory management models cannot explain the intraday behaviour of liquidity. Instead, in line with Ho and Stoll (1983), option liquidity is expected 
to be primarily determined by option volatility. The latter notion has been mainly associated with information asymmetries (see Wyart et al., 2008) but also with the derivatives hedging theory (see Engle and Neri, 2010 and Cho and Engle, 1999). In order to investigate this hypothesis, we estimate the following regression for intraday option liquidity and option volatility:

$$
\text { Stnd_ } V_{t}=a_{0}+\sum_{i=1}^{101} \alpha_{i} D_{t}+\epsilon_{t}
$$

Stnd_ $V_{t}$ refers to the t-th observation of the standardised variable (PBAS, Depth, Volatility). $D_{t}$ refers to dummy variables for each 5-minute interval t. In total there are 1015 -minute intervals during the trading day, but we omit the interval at the middle of the day (12:0012:05) which is captured by the coefficient $\alpha_{0}$. When presenting the results, the coefficient for each intraday interval is the sum of the regression coefficient for that interval and the constant, therefore we drop the constant from the figures. Equation (3) is estimated with the Newey-West correction. Results for Equation (3) are presented in Figure 1. ${ }^{15}$

$$
\text { *** insert Figure } 1 \text { here*** }
$$

For the US options market, Engle and Neri (2010) show that spreads are wider in the morning and widen again at the end of the trading day, nonetheless not to the same level. For a

\footnotetext{
${ }^{15}$ In order to conserve space, Figures 1-3 only present the results for call contracts. The results for put contracts are very similar and are available upon request.
} 
competitive dealer market, Frino et al. (2008) report an increase in depth and a narrowing of the bid-ask spreads at the market close, a finding that they attribute to inventory management practices. Importantly, the authors show that the pattern of intraday spreads cannot be attributed to the pattern of intraday volatility. In light of the findings by Frino et al. (2008), spreads and depths at NYSE LIFFE are expected to reflect two dimensions of liquidity and hence to move in opposite directions during the day. Also, according to the inventory management theory, both liquidity and volatility measures should increase at the market close. However, in contrast to competitive dealer markets, in this study, it is hypothesized that market maker influence diminishes under a "decentralized" trading system (such as NYSE LIFFE). If inventory risk is not important, then liquidity should not be affected at the market close.

For all three markets, spreads are at their widest level at the beginning of the trading day. For Amsterdam, spreads remain elevated and significant until 09:30, however for London and Paris, spreads reach their daily average levels in the first 30 minutes of trading. During the morning session, spreads decline monotonically, a process that is only interrupted by clear drops in liquidity at 09:00, 09:30 and 10:00. All three times coincide with macroeconomic announcements. A less pronounced drop in liquidity is documented at 12:30. During the afternoon session, two clear sudden falls in liquidity emerge. The first at 13:30 coincides with the US market open. Also, the second spike coincides with US scheduled macroeconomic announcements. No significant variation from the mean is observed at the market close. This latter finding is in contrast with the findings of Lee et al. (1993) for NYSE (a specialist market), where a U-shape spread pattern is observed. However, the results also differ from Chan, Chung and Johnson (1995) for the CBOE and Frino et al. (2008) for the SFE, two competitive dealer markets. This finding supports the hypothesis that inventory risk is not important for NYSE LIFFE equity options. 
*** insert Figure 2 here***

The results for quoted depth are presented in Figure 2. For Amsterdam and Paris, depth is reciprocal to spreads and follows the reverse pattern during the trading day. At market open, Amsterdam (Paris) depth is approximately 1.9 (1.3) standard deviations below the daily mean. However, for London, depth is higher than the daily mean at the market open and remains high during the morning session. Except for London, depth is at its lowest levels at the market open and increases sharply after the first hour of trading. A very clear inverse association between the spread and depth measures emerges. Vijh (1990) shows that in competitive dealer markets, spreads and depths have a positive association which reflects the costs of carrying more inventory. This finding is strongly disputed here for the NYSE LIFFE for Amsterdam and Paris. Market depth remains stable throughout the trading day and is low at the market close for Amsterdam only. As with the spread measures, these results on depth at the market close are not consistent with the findings of prior literature for the NYSE, a specialist market, (widening spread, decrease in depth (Lee et al., 1993)) nor results for the SFE (narrowing spread, increase in depth (Frino et al., 2008)), a competitive dealer market. Both studies agree that the volatility in the spread and depth measures at the market close is related to market structure differences, as the monopolistic power of dealers on the NYSE widens spreads at the market close, whilst the competitive presence of market makers at the CBOE and SFE drive spreads narrower. Our results are consistent with the hypothesis that market maker influence diminishes in the market structure employed by NYSE LIFFE for the European equity options and are also consistent with Engle and Neri's (2010) view that option traders manage their risks by hedging their positions in the underlying market. 
Figure 3 presents the intraday patterns for option volatility. Across all three markets, volatility is high at the market open and reduces gradually for the remainder of the morning session. Considering the time intervals with a sudden widening in spreads in Figure 1, we see that this is associated with volatility in the following interval. This spike in volatility implies a contemporaneous rather a lagged effect that arises from the calculation of volatility as the absolute return between two consecutive intervals. Similarly, option volatility increases sharply during the interval following the US market open and also at 15:05 related to the US market events.

\footnotetext{
*** insert Figure 3 here***
}

So far in this section, we fail to provide evidence regarding the influence of inventory management in equity options liquidity during the trading day. Instead, the findings are in line with the prediction of Ho and Stoll (1983), (and empirically those of Wei and Zheng, 2010) for a competitive dealer market. Option volatility appears to be the most important determinant of liquidity in a hybrid market such as for equity options trading at NYSE LIFFE. We discuss these findings further in the multivariate analysis below.

Proceeding from this, we aim to more formally establish the intraday determinants of equity option liquidity (Hypothesis 2). We estimate the following regression:

$$
\begin{aligned}
\text { PBAS }_{t}=a_{0}+ & \sum_{i=1}^{6} \alpha_{i} P B A S_{t-i}+a_{7} \text { Volt }_{t} \\
& +a_{8} \text { Vlm }_{t}+a_{9} \operatorname{Tr}_{t}+a_{10} \text { TTM }_{t}+a_{11} \text { Mon }_{t}+a_{12} \text { Dur }_{t}+\epsilon_{t}
\end{aligned}
$$


Where $P B A S$ refers to percentage quoted bid-ask spread. Lagged values of the dependent variable to capture autocorrelation effects. ${ }^{16}$ Volt refers to the absolute return which is used as a measure of volatility, Vlm refers to the natural logarithm of the average quoted volume, and Tr refers to transaction frequency. TTM and Mon are control variables that refer to time-tomaturity in days and moneyness, respectively. Dur refers to the number of minutes between trades during a trading day. All estimations are reported with Newey-West standard errors. The results are presented in Table 3 .

$* * *$ insert Table 3 here $* * *$

Consistent with Danielsson and Payne (2012) for the FX market, the results confirm the hypothesis that spreads widen during volatile intraday intervals. We report a positive sign for quoted volume for Amsterdam calls, while negative signs for London and Paris. The volatility and volume findings for Amsterdam generally confirm that inventory management effects are not strong for that market. One possible explanation for this is the popularity of equity options contracts with retail investors in Amsterdam. These findings are consistent with information asymmetry models and the derivatives hedging theory (see Wyart et al., 2008 and Engle and Neri, 2010). For Paris and London, volume is negatively associated with spreads, a finding that is in line with inventory management (see Wei and Zheng, 2010). In order to study this effect further, we regress traded spreads (effective half-spreads) against traded volume. The results show that traded volume is positively associated with spreads,

\footnotetext{
16 The selection of the lag order does not materially change the results.
} 
which further supports the information asymmetry hypothesis (results not reported to conserve space). Transaction frequency reflects order processing costs and spreads are expected to widen when the number of trades decreases. This hypothesis is confirmed for Amsterdam calls only.

As hypothesized, near-maturity options exhibit wider spreads. This is in line with Cho and Engle's (1999) hypothesis that American-style options that are near maturity are more likely to be exercised and this will increase the difficulty for market makers to maintain their hedged positions, hence a negative sign would be expected. The coefficient for moneyness is negative and highly significant for 5 of 6 cases, confirming the leverage effect and option return volatility hypothesis from Wei and Zheng (2010). ${ }^{17}$ Dufour and Engle (2000) show that spreads are positively correlated with durations. Consistent with their findings, we show that the coefficient for duration is positive and significant for the more frequently traded markets (Amsterdam and London).

\subsection{The effect of macro-economic news on intraday equity option liquidity}

*** insert Table 4 here***

In this section we initially investigate which news announcements affect intraday equity option liquidity (Hypothesis 3). Equation (5) includes intraday event dummies to capture the

\footnotetext{
${ }^{17}$ In a separate set of regressions, we also confirm the findings of Cho and Engle (1999) and Engle and Neri (2010) that PBAS is convex in moneyness and time to maturity (results not presented but available on request).
} 
effects of specific announcements on liquidity. We use country-specific events along with European Union and US events. Table 4 presents the type and time of each announcement category. All announcements are downloaded from Bloomberg, and we used Bloomberg's relevance index to identify the most important macroeconomic announcements. In total, we use 18 event dummies. For Paris, all macroeconomic announcements are released before the market opens. All times are GMT. Each equation is estimated using OLS and Newey-West standard errors are reported. We also estimate the same regressions but with depth as the dependent variable. The results are similar but are not presented here in order to conserve space (available upon request). We estimate the following regression:

$$
\begin{aligned}
& \text { PBAS }_{t}=a_{0}+ \sum_{i=1}^{6} \alpha_{i} \text { PBAS } \\
& t-i \\
&+\sum_{i=7}^{12} \alpha_{i} \text { Control }_{i}+\sum_{i=13}^{16} \alpha_{i} \text { Country }_{i}+\sum_{i=17}^{23} \alpha_{i} \text { Euro }_{i}+\sum_{i=24}^{30} \alpha_{i} U S_{i}+\epsilon_{t}
\end{aligned}
$$

Where PBAS refers to percentage bid-ask spread. Control refers to the exogenous variables from Equation (4). Country, Euro and US refer to the country-specific, European Unionspecific and US-specific set of dummy variables (identified in Table 4). The coefficients on the macroeconomic announcement dummies are presented in Table 5.

*** insert Table 5 here*** 
For the country-specific dummies, CPI and GDP announcements lead to decreased liquidity for London puts and London calls respectively. Unemployment news is positively associated with liquidity for London and negatively for Amsterdam. European Central Bank interest rate announcements lead to a widening of the spread for Amsterdam puts and Paris calls. ${ }^{18}$ Clearly, European CPI and Industrial Production announcements have a strong effect on option liquidity but we fail to provide similar evidence for the Euro-wide GDP announcements. The money supply dummy remains insignificant for 5 of 6 regressions and the European trade balance indicator announcements are positive and highly significant for Amsterdam only. It is clear that the market is strongly influenced by US announcements. In particular, the coefficients on four of six US macroeconomic events are positive and highly significant (CPI, GDP, InProd and Lead), especially for the most liquid Amsterdam and London markets. As anticipated, the US open market dummy has a strong and positive relation with option liquidity.

Having established that macroeconomic news can be considered as liquidity shocks, we establish how long it takes for liquidity to revert back to its "normal" level after a news shock. ${ }^{19}$ The procedure we adopt to establish shock duration is visually described in Figure 4 .

$* * *$ insert Figure 4 here***

\footnotetext{
${ }^{18}$ In separate regressions, we also confirm this finding for the Bank of England interest rate and UK money supply announcements.

${ }^{19} \mathrm{We}$ are grateful to an anonymous referee for this suggestion.
} 
Controlling for the macroeconomic shocks, the path of PBAS can be forecasted from the autoregressive coefficients of Equation (5). For example, given knowledge of the average PBAS in the time periods prior to an event, we can forecast the spread as the weighted sum of means of the autoregressive coefficients plus the constant term. This is represented by the dotted line in Figure 4 and denotes the "normal" path the PBAS would have taken had an event not occurred. ${ }^{20}$ Having established the "normal" path of PBAS, we are then able to compare it with the "realized" path that represents the mean PBAS in the intervals after each shock. That comparison would then denote the duration of the shock. We estimate the results for each news source, however for simplicity we only report the group results to Country-, Euro- and US-specific shocks and also separately for the US market open. The results are presented in Figure 5.

$$
\text { *** insert Figure } 5 \text { here*** }
$$

The results show that the effects of news are generally short-lived. In the case of Country and EU effects, shocks usually disappear within 5 minutes, a finding which is consistent across all markets and contract types. However, for the US news and US equity market opening time, shocks are more persistent. In general, bid-ask spreads revert back to their "normal" levels within 10 minutes of the release time.

${ }^{20}$ Clearly the spread could have any slope and the positive slope is only used here as an example. 
A final question regarding the effect of macroeconomic news on equity option liquidity is the extent of any cross-country effect. For example, do the UK macroeconomic announcements impact the French equity options market? We estimate the following regression.

PBAS $_{t}=a_{0}+\sum_{i=1}^{6} \alpha_{i} P B A S_{t-i}+\sum_{i=7}^{12} \alpha_{i}$ Control $_{i}+\sum_{i=13}^{30} \alpha_{i}$ Macro $_{i}+\sum_{i=31}^{34} \alpha_{i}$ Cross $_{i}+\epsilon_{t}$

Where PBAS refers to percentage bid-ask spread. Control refers to the exogenous variables in Equation 4. Macro refers to the country-specific, European Union-specific and US-specific set of dummy variables (identified in Table 4). Cross refers to a set of dummy variables that capture possible cross-country effects. For example, for Amsterdam, we add a set of dummies that refer to the UK macroeconomic news announcements. For Paris, all macroeconomic announcements are made prior to the market opening, hence there are no cross-country dummy variables. The results are presented in Table 6 .

*** insert Table 6 here $* * *$

In general, UK CPI and GDP announcements have a spill-over effect on the equity option liquidity of the Dutch and French markets. In contrast, London liquidity is only partially affected by the Amsterdam Trade Balance announcements. The results also confirm that put 
contracts react more strongly to cross-country effects and cross-country events typically increase option liquidity. The additional explanatory power from the cross-country effects is modest.

\subsection{Commonality in intraday equity option liquidity}

The above results confirm the hypothesis that equity options are prone to market-wide effects during the trading day that strongly determine the intraday pattern of option liquidity. To explore this further, this section studies commonality in liquidity across options contracts by constructing plots of systematic liquidity during the trading day (Hypothesis 4). We employ Principal Component Analysis (PCA) to infer the intraday commonality in liquidity. The procedure is as follows. First, we apply the PCA to 30-minute intervals since there are not enough observations to guarantee a continuous sample at a higher frequency. In total, there are seventeen 30-minute intervals $(n)$ during the trading day. $\mathrm{N}$ is the total number of days in the sample, hence the total number of 30 -minute intervals is $\mathrm{N} \times \mathrm{n}$. We treat each interval independently and in order to accommodate missing data, we apply two criteria. First, for each interval, we only use tickers that report quotes for $80 \%$ of the number of days. Second, we interpolate missing values by using the mean liquidity estimate per interval. This allows us to retain the maximum number of tickers per interval and also use a $\mathrm{n} x$ i matrix where the number of intervals $(n)$ is greater than the number of tickers $(i)$. All ticker measures are standardized by the daily mean and daily standard deviation per ticker in order to avoid overweighting because of scale differences (see Korajczyk and Sadka, 2008; Dunne et al., 2011). 
For each trading day, we extract the first three principal components. We plot the proportion of variance explained by the first principal factor in Figure 6.

$* * *$ insert Figure 6 here***

For Amsterdam, the proportion of variance explained by the first principal factor is on average $12 \%$ for calls and $11 \%$ for puts, nevertheless systematic liquidity varies considerably during the trading day. Thus, in the first 30 minutes of trading the proportion of systematic liquidity is $21 \%$ for both calls and puts and follows a U-shape pattern with a low of $7 \%$ for calls and $6.5 \%$ for puts at 11:30. A second peak in systematic liquidity is observed at 15:00. For London, the average figures are $14 \%$ for calls and $13 \%$ for puts. Clearly systematic liquidity is at its highest level at the market open and levels off during the day with two distinctive peaks at 13:30 and 15:00. Finally, the average systematic liquidity figure for Paris is $16 \%$ for both calls and puts. The proportion of systematic liquidity is on average $27 \%$ at the market open and in contrast to the other markets, the Paris market appears to have additional elevated systematic liquidity at 10:00 and 12:00. The common peaks across the three plots correspond to overnight information arrival and the US equity market opening, which are logical sources of systematic movements. 


\section{Conclusions}

For option markets, the literature on liquidity is very thin. To our knowledge, there are no prior studies on the intraday determination of equity option liquidity. This paper focuses on two main aspects of option liquidity: (i) the intraday behaviour of equity option liquidity and its determinants and (ii) the influence of macro-economic events and commonality on intraday equity option liquidity. We contribute to the options market microstructure literature in several respects explained below.

We examine the intraday patterns of liquidity and volatility at NYSE LIFFE, an electronic, order-driven market with registered trading members and competing liquidity providers. This is crucial in order to determine the influence of the order book on inventory management. We contest the claim made in Frino et al. (2008) that inventory management models explain the intraday variations in option spreads and depths. Option liquidity measures are strongly correlated with option volatility. We suggest that this finding reflects the practices of traders who manage their risks by hedging their positions in the underlying market (see Engle and Neri, 2010). This explains why our results differ from the intraday pattern of liquidity measures observed by Frino et al. (2008) for the SFE and also explains why intraday spreads decrease monotonically on NASDAQ (see Chan, Christie and Schultz, 1995) but are correlated with volatility on CBOE (see Chan, Chung and Johnson, 1995) and NYSE LIFFE.

We show that the option liquidity measures are strongly correlated with option volatility. For Amsterdam, in contrast to the expected outcome if inventory risk were an important component of the bid-ask spread, increases in volume and volatility are associated with decreases in liquidity. These findings are in line with information asymmetry models and the derivatives hedging theory. For London and Paris, we find evidence to support both the information asymmetry and inventory management models. 
We study the reaction of option liquidity to a series of macroeconomic events. Option liquidity reacts strongly to US macroeconomic news announcements. Also, the average systematic liquidity component is $12 \%$ for Amsterdam, $14 \%$ for London and $16 \%$ for Paris. Systematic liquidity varies considerably during the trading day and is at its highest level during the market open then levels off during the day with two distinctive peaks at 13:30 and 15:00.

This is the first paper to use such a comprehensive dataset of quotes and trades to study individual equity option liquidity. Our findings imply a clear need for richer models of intraday volatility to incorporate liquidity spill-over effects. Finally, the extent to which equity option spreads respond to macroeconomic news announcements has not been previously studied, and this aspect sheds more light on the intraday determination of option liquidity and the systematic component of liquidity.

Wei and Zheng (2010) present the view that "the quest for understanding option market liquidity has just begun." This study sheds new light on the elusive concept of intraday option liquidity and the identification of its determinants. 


\section{References}

Amihud, Y. and H. Mendelson, 1982. Asset price behaviour in a dealership market, Financial Analysts Journal, 38, 50-59.

Cao, M. and J. Wei, 2010. Option market liquidity: Commonality and other characteristics, Journal of Financial Markets, 13, 20-48.

Chan, K. C., Christie, W. G. and P. Schultz, 1995. Market structure and the intraday pattern of bid-ask spreads for NASDAQ securities, Journal of Business, 68, 35-60.

Chan, K., Chung, Y. P. and H. Johnson, 1995. The intraday behaviour of bid-ask spreads for NYSE stocks and CBOE options, Journal of Financial and Quantitative Analysis, 30, 329-346.

Charoenwong, C. and K. H. Chung, 2000. An empirical analysis of quoted depths of NYSE and AMEX stocks, Review of Quantitative Finance and Accounting, 14, 85-102.

Cho, Y. H. and R. Engle, 1999. Modelling the impacts of market activity on bid-ask spreads in the option market, Working paper, National Bureau of Economic Research, 7331.

Chordia, T., Roll, R. and A. Subrahmanyam, 2000. Commonality in liquidity, Journal of Financial Economics, 56, 3-28.

Chordia, T., Roll, R. and A. Subrahmanyam, 2001. Market liquidity and trading activity, Journal of Finance, 56, 501-530.

Chung, K. H. and X. Zhao, 2004. Making a market with spreads and depth, Journal of Business Finance and Accounting, 31, 1069-1096.

Danielsson J. and R. Payne, 2012. Liquidity determination in an order-driven market, European Journal of Finance, 18, 799-821.

Dominguez, K. and F. Panthaki, 2006. What defines `news' in foreign exchange markets?, Journal of International Money and Finance, 25, 168-198. 
Dufour, A. and R. Engle, 2000. Time and the price impact of a trade, Journal of Finance, 55, 2467-2498.

Dunne, P., Moore, M. and V. Papavassiliou, 2011. Commonality in returns, order flows, and liquidity in the Greek stock market, European Journal of Finance, 17, 577-587.

Engle, R. and B. Neri, 2010. The impact of hedging costs on the bid and ask spread in the options market. Working Paper, New York University.

Fleming, M. J. and N. Krishnan, 2012. The microstructure of the TIPS market, FRBNY Economic Policy Review, March, 27-45.

Fleming, M. J. and E. M. Remolona, 1999. Price formation and liquidity in the U.S. Treasury market: The response to public information, Journal of Finance, 55, 1901-1915.

Frino, A., Lepone, A. and G. Wearin, 2008. Intraday behaviour of market depth in a competitive dealer market: A note, Journal of Futures Markets, 28, 294-307.

George, T. J. and F. A. Longstaff, 1993. Bid-ask spreads and trading activity in the S\&P 100 index options market, Journal of Financial and Quantitative Analysis, 28, 381-397.

Glosten, L. R. and P. R. Milgrom, 1985. Bid, ask and transaction prices in a specialist market with heterogeneously informed trades, Journal of Financial Economics, 14, 71-100.

Gregoriou, A., (forthcoming). Market quality of dealer versus hybrid markets for illiquid securities: new evidence from the FTSE AIM Index, European Journal of Finance.

Harris, L. E. 1990. Liquidity, trading rules and electronic trading systems. New York University Monograph Series in Finance and Economics, No. 1990-4.

Hasbrouck, J. and D. J. Seppi, 2001. Common factors in prices, order flows, and liquidity, Journal of Financial Economics, 59, 383-411.

Ho, T. and H. R. Stoll, 1981. Optimal dealer pricing under transactions and return uncertainty, Journal of Financial Economics, 9, 47-73. 
Ho, T. and H. R. Stoll, 1983. The dynamics of dealer markets under competition, Journal of Finance, 38, 1053-1074.

Huberman, G. and D. Halka, 2001. Systematic liquidity, Journal of Financial Research, 24, 161-178.

Korajczyk, R. and R. Sadka, 2008. Pricing the commonality across alternative measures of liquidity, Journal of Financial Economics, 87, 45-72.

Kyle, A. S., 1985. Continuous auctions and insider trading, Econometrica, 53, 1315-1336.

Lee, C., Mucklow, B. and M. J. Ready, 1993. Spreads, depths, and the impact of earnings information: An intraday analysis, Review of Financial Studies, 6, 345-374.

Montalvo, J., 2003. Liquidity and market makers: A pseudo-experimental analysis with ultrahigh frequency data, European Journal of Finance, 9, 358-378.

Neal, R. 1992. A comparison of transaction costs between competitive market maker and specialist structures, Journal of Business, 65, 317-334.

Pardo, A. and R. Pascual, 2012. On the hidden side of liquidity, European Journal of Finance, 18, 949-967.

Petrella, G. 2006. Option bid-ask spread and scalping risk: Evidence from a covered warrants market, Journal of Futures Markets, 26, 843-867.

Riordan, R., Storkenmaier, A, Wagener, M and S. Zhang, 2013. Public information arrival: Price discovery and liquidity in electronic limit order markets, Journal of Banking \& Finance, 37, 1148-1159.

Vijh, A. 1990. Liquidity of the CBOE equity options. Journal of Finance, 45, 1157-1179.

Wei, J. and J. Zheng, 2010. Trading activity and bid-ask spreads of individual equity options, Journal of Banking \& Finance, 34, 2897-2916. 
Wyart, M., Bouchaud, J., Kockelkoren, J., Potters, M. and M. Vettorazzo, 2008. Relation between bid-ask spread, impact and volatility in order-driven markets, Quantitative Finance, 8, 41-57. 


\begin{tabular}{|c|c|c|c|c|c|c|}
\hline \multicolumn{7}{|c|}{$\begin{array}{c}\text { Table } 1 \\
\text { Descriptive statistics } \\
\end{array}$} \\
\hline & \multicolumn{2}{|c|}{ Amsterdam } & \multicolumn{2}{|c|}{ London } & \multicolumn{2}{|c|}{ Paris } \\
\hline & Call & Put & Call & Put & Call & Put \\
\hline \multicolumn{7}{|c|}{ Panel A } \\
\hline No. of days & \multicolumn{2}{|c|}{709} & \multicolumn{2}{|c|}{709} & \multicolumn{2}{|c|}{714} \\
\hline No. of tickers & $65(72)$ & $65(72)$ & 99 (106) & $99(106)$ & $59(70)$ & $59(70)$ \\
\hline \multicolumn{7}{|c|}{ Panel B } \\
\hline \multicolumn{7}{|l|}{ Spread } \\
\hline Mean & 12.18 & $11.41 * * *$ & 18.20 & $16.78 * * *$ & 13.90 & $12.78 * * *$ \\
\hline Min & 5.28 & 5.59 & 6.10 & 5.99 & 6.23 & 5.58 \\
\hline Max & 66.15 & 60.64 & 88.31 & 79.42 & 63.38 & 55.55 \\
\hline STD & 2.88 & 2.74 & 5.22 & 4.97 & 3.23 & 3.02 \\
\hline \multicolumn{7}{|l|}{ Depth } \\
\hline Mean & 555.88 & $572.66^{* * *}$ & 24.61 & 24.59 & 69.41 & $69.27 * * *$ \\
\hline Min & 22.50 & 22.50 & 5.00 & 5.00 & 21.67 & 21.67 \\
\hline Max & 1523.71 & 1586.00 & 96.29 & 101.04 & 159.60 & 276.02 \\
\hline STD & 156.74 & 157.54 & 8.28 & 8.35 & 9.37 & 9.27 \\
\hline \multicolumn{7}{|c|}{ Panel C } \\
\hline Volatility & 1.60 & $1.43 * * *$ & 1.88 & $1.67 * * *$ & 1.75 & $1.55 * * *$ \\
\hline Volume & 266.44 & $209.30 * * *$ & 39.92 & $35.31 * * *$ & 110.79 & $98.26 * * *$ \\
\hline No. of Trades & 7.88 & $5.68 * * *$ & 0.79 & $0.63 * * *$ & 0.79 & $0.67 * * *$ \\
\hline Duration & 14.26 & $18.05 * * *$ & 43.68 & $49.48 * * *$ & 38.92 & $42.68 * * *$ \\
\hline \multicolumn{7}{|c|}{$\begin{array}{l}\text { Number of days refer to the total number of trading days in the sample. Number of tickers refers to the total number of firm-options } \\
\text { trading at the exchanges and includes delisted options. The figures in parentheses are the number of tickers in the raw dataset prior to } \\
\text { application of our selection criteria. Spread refers to percentage quoted spread. Depth is calculated from the average of bids plus asks } \\
\text { per five minute interval. Intraday volatility is estimated from } 5 \text {-minute absolute returns. Volume refers to the average traded volume } \\
\text { per interval. Number of trades refer to transaction frequency per } 5 \text {-minute interval which is calculated as the total number of trades } \\
\text { over the total number of date-time intervals. Duration is measured in minutes and refers to the average time between trades. } * * * \text { denote } \\
\text { a significant difference in means between calls and puts at the } 1 \% \text { level. }\end{array}$} \\
\hline
\end{tabular}




\begin{tabular}{|c|c|c|c|c|c|c|}
\hline \multicolumn{7}{|c|}{$\begin{array}{c}\text { Table } 2 \\
\text { Liquidity by volatility, volume and transaction frequency }\end{array}$} \\
\hline \multicolumn{7}{|c|}{$\begin{array}{l}\text { Liquidity by volatility, volume and transaction frequency } \\
\text { Quintile }\end{array}$} \\
\hline & & 1 & 2 & 3 & 4 & 5 \\
\hline \multicolumn{7}{|c|}{ Amsterdam } \\
\hline \multirow[t]{3}{*}{ Spread } & Volatility & $11.24(10.73)$ & $11.52(10.89)$ & $11.94(11.17)$ & $12.50(11.60)$ & $13.72(12.64)$ \\
\hline & Volume & $11.92(11.11)$ & $12.11(11.39)$ & $12.18(11.51)$ & $12.31(11.56)$ & $12.46(11.66)$ \\
\hline & No. of Trades & $11.90(11.06)$ & $12.08(11.33)$ & $12.18(11.49)$ & $12.31(11.65)$ & $12.64(11.94)$ \\
\hline \multirow[t]{3}{*}{ Depth } & Volatility & $610.11(624.61)$ & $567.21(586.19)$ & $552.72(570.12)$ & $544.95(559.87)$ & $504.56(522.77)$ \\
\hline & Volume & $591.83(605.40)$ & $569.92(586.54)$ & $554.84(575.19)$ & $536.49(549.41)$ & $513.16(523.09)$ \\
\hline & No. of Trades & $597.70(612.58)$ & $569.28(585.14)$ & $552.09(565.7)$ & $531.09(542.65)$ & $495.64(503.71)$ \\
\hline \multicolumn{7}{|l|}{ London } \\
\hline \multirow[t]{3}{*}{ Spread } & Volatility & $15.60(14.26)$ & $16.67(15.22)$ & $17.59(16.32)$ & $19.04(17.67)$ & $21.84(20.24)$ \\
\hline & Volume & $18.22(16.92)$ & $18.54(17.22)$ & $18.51(17.19)$ & $18.71(17.31)$ & $18.95(17.11)$ \\
\hline & No. of Trades & $18.43(17.05)$ & $18.63(17.32)$ & $18.91(17.23)$ & $18.83(17.23)$ & $18.83(17.23)$ \\
\hline \multirow[t]{3}{*}{ Depth } & Volatility & $25.66(25.41)$ & $24.59(24.55)$ & $24.40(24.46)$ & $24.22(24.36)$ & $24.18(24.16)$ \\
\hline & Volume & $24.22(24.26)$ & $23.98(24.10)$ & $24.00(23.86)$ & $24.27(24.32)$ & $24.49(24.88)$ \\
\hline & No. of Trades & $24.30(24.32)$ & $24.08(24.28)$ & $24.03(24.18)$ & $24.01(24.18)$ & $24.01(24.18)$ \\
\hline \multicolumn{7}{|l|}{ Paris } \\
\hline \multirow[t]{3}{*}{ Spread } & Volatility & $12.24(11.28)$ & $13.24(12.19)$ & $13.84(12.76)$ & $14.45(13.32)$ & $15.67(14.25)$ \\
\hline & Volume & $14.01(12.91)$ & $14.07(12.92)$ & $14.13(12.92)$ & $14.21(12.93)$ & $14.36(12.82)$ \\
\hline & No. of Trades & $14.04(12.88)$ & $14.14(12.92)$ & $14.28(12.95)$ & $14.45(12.93)$ & $14.45(12.93)$ \\
\hline \multirow[t]{3}{*}{ Depth } & Volatility & $71.01(71.08)$ & $70.04(69.84)$ & $69.60(69.39)$ & $68.91(68.82)$ & $67.52(67.29)$ \\
\hline & Volume & $69.42(69.25)$ & $69.35(69.23)$ & $69.22(69.35)$ & $69.37(69.24)$ & $70.28(69.90)$ \\
\hline & No. of Trades & $69.48(69.39)$ & $69.56(69.53)$ & $69.45(69.45)$ & $69.73(69.15)$ & $69.73(69.15)$ \\
\hline
\end{tabular}


Table 3

Determinants of the quoted bid-ask spread

\begin{tabular}{|l|c|c|c|c|c|c|}
\hline & \multicolumn{2}{|c|}{ Amsterdam } & \multicolumn{2}{c|}{ London } & \multicolumn{2}{c|}{ Paris } \\
\hline & Call & Put & Call & Put & Call & Put \\
\hline Volt & 0.15 & 0.12 & 0.36 & 0.28 & 0.49 & 0.36 \\
\hline & $(15.04)^{* * *}$ & $(12.79)^{* * *}$ & $(12.10)^{* * *}$ & $(7.83)^{* * *}$ & $(19.84)^{* * *}$ & $(11.07)^{* * *}$ \\
\hline Vlm & 0.10 & $-1.36 \mathrm{E}-02$ & -0.21 & -0.33 & -0.58 & -1.74 \\
\hline & $(3.25)^{* * *}$ & $(-0.47)$ & $(-3.61)^{* * *}$ & $(-5.16)^{* * *}$ & $(-3.21)^{* * *}$ & $(-9.66)^{* * *}$ \\
\hline Tr & 0.03 & $-2.65 \mathrm{E}-03$ & $8.28 \mathrm{E}-03$ & -0.08 & $2.36 \mathrm{E}-03$ & -0.07 \\
\hline & $(3.70)^{* * *}$ & $(-0.37)$ & $(0.31)$ & $(-3.07)^{* * *}$ & $(0.10)$ & $(-2.67)^{* * *}$ \\
\hline TTM & -0.02 & -0.02 & -0.02 & -0.02 & -0.03 & -0.04 \\
\hline & $(-26.73)^{* * *}$ & $(-28.39)^{* * *}$ & $(-9.14)^{* * *}$ & $(-12.01)^{* * *}$ & $(-11.03)^{* * *}$ & $(-12.64)^{* * *}$ \\
\hline Mon & -71.81 & 67.91 & -78.72 & 101.30 & -78.29 & 106.90 \\
\hline & $(-43.83)^{* * *}$ & $(41.00)^{* * *}$ & $(-12.53)^{* * *}$ & $(14.17)^{* * *}$ & $(-15.78)^{* * *}$ & $(18.78)^{* * * *}$ \\
\hline Dur & $5.04 \mathrm{E}-04$ & $8.12 \mathrm{E}-04$ & $8.29 \mathrm{E}-04$ & $5.62 \mathrm{E}-04$ & $4.20 \mathrm{E}-05$ & $1.64 \mathrm{E}-04$ \\
\hline & $(2.52)^{* *}$ & $(5.21)^{* * *}$ & $(3.97)^{* * *}$ & $(2.74)^{* * *}$ & $(0.25)$ & $(0.88)$ \\
\hline Lags 1-6 & YES & YES & YES & YES & YES & YES \\
\hline Constant & 73.43 & -65.45 & 82.05 & -97.43 & 85.30 & -93.69 \\
\hline & $(44.14)^{* * *}$ & $(-39.27)^{* * *}$ & $(13.30)^{* * *}$ & $(-13.53)^{* * *}$ & $(17.97)^{* * *}$ & $(-16.74)^{* * *}$ \\
\hline Adj-R & 0.76 & 0.76 & 0.80 & 0.81 & 0.53 & 0.53 \\
\hline The & & & & & \\
\hline
\end{tabular}

The dependent variable is $P B A S$ which refers to percentage quoted bid-ask spread. Intraday volatility (Volt) is estimated from 5-minute absolute returns. Vlm and Tr refer to the natural logarithm of the average quoted volume and the transaction frequency per 5-minute interval. TTM and Mon are exogenous variables that refer to time-to-maturity in days and moneyness respectively. Dur refers to duration that is measured in minutes and refers to the average time between trades. Each equation is estimated using OLS and Newey-West standard errors are reported. T-statistics in parentheses. *,**,*** denote significance at $10 \%, 5 \%$ and $1 \%$ levels, respectively. 


\begin{tabular}{|c|c|c|c|c|}
\hline \multicolumn{5}{|c|}{$\begin{array}{c}\text { Table } 4 \\
\text { Macroeconomic announcement type and time (GMT) }\end{array}$} \\
\hline Announcement & Dummy & Amsterdam & London & Paris \\
\hline \multicolumn{5}{|c|}{ Country-specific } \\
\hline CPI & $\mathrm{CPI}_{\mathrm{Co}}$ & $08: 30$ & 09:30 & . \\
\hline GDP & $\mathrm{GDP}_{\mathrm{Co}}$ & $08: 30$ & 09:30 & . \\
\hline Unemployment rate & UnRate $_{\mathrm{Co}}$ & $08: 30$ & $09: 30$ & . \\
\hline Trade Balance & $\mathrm{TrBal}_{\mathrm{Co}}$ & 08:30 & 09:30 & . \\
\hline \multicolumn{5}{|c|}{ European Union } \\
\hline Interest Rate & IntRate $_{\mathrm{EU}}$ & $12: 45$ & $12: 45$ & $12: 45$ \\
\hline CPI & $\mathrm{CPI}_{\mathrm{EU}}$ & $10: 00$ & $10: 00$ & $10: 00$ \\
\hline GDP & $\mathrm{GDP}_{\mathrm{EU}}$ & $10: 00$ & $10: 00$ & $10: 00$ \\
\hline Industrial Production & IndProd $_{\mathrm{EU}}$ & $10: 00$ & $10: 00$ & $10: 00$ \\
\hline M3 & M3 & 09:00 & 09:00 & 09:00 \\
\hline Trade Balance & TrBal $_{\mathrm{EU}}$ & $10: 00$ & $10: 00$ & 10:00 \\
\hline Unemployment rate & UnRate $_{\mathrm{EU}}$ & $10: 00$ & $10: 00$ & $10: 00$ \\
\hline \multicolumn{5}{|c|}{ US } \\
\hline CPI & $\mathrm{CPI}_{\mathrm{US}}$ & $13: 30$ & $13: 30$ & $13: 30$ \\
\hline GDP & GDP $_{\text {US }}$ & $13: 30$ & $13: 30$ & $13: 30$ \\
\hline Industrial Production & IndProd $_{\text {US }}$ & $14: 15$ & $14: 15$ & $14: 15$ \\
\hline Leading indicators & Lead & $15: 00$ & 15:00 & $15: 00$ \\
\hline Trade Balance & TrBalus $_{\text {U }}$ & $13: 30$ & $13: 30$ & $13: 30$ \\
\hline Unemployment rate & UnRate $_{\text {US }}$ & $13: 30$ & $13: 30$ & $13: 30$ \\
\hline US opening time & US open & $13: 30$ & $13: 30$ & $13: 30$ \\
\hline \multicolumn{5}{|c|}{$\begin{array}{l}\text { CPI refers to Consumer Price Index and GDP is Gross Domestic Product. M3 refers to money supply fo } \\
\text { the European Union. Interest rate refers to the ECB interest rate announcements. Leading indicator } \\
\text { refers to an index that is designed to track the performance of the US economy. All announcements ar } \\
\text { downloaded from Bloomberg. We used Bloomberg's relevance index to identify the most importan } \\
\text { macroeconomic announcements. For Paris, all macroeconomic announcements are made before th } \\
\text { market opens. }\end{array}$} \\
\hline
\end{tabular}




\begin{tabular}{|c|c|c|c|c|c|c|}
\hline \multicolumn{7}{|c|}{$\begin{array}{c}\text { Table } 5 \\
\text { Macroeconomic events }\end{array}$} \\
\hline & \multicolumn{2}{|c|}{ Amsterdam } & \multicolumn{2}{|c|}{ London } & \multicolumn{2}{|c|}{ Paris } \\
\hline & Call & Put & Call & Put & Call & Put \\
\hline \multirow[t]{2}{*}{$\mathrm{CPI}_{\mathrm{Co}}$} & -0.51 & 0.05 & 2.02 & 2.29 & & \\
\hline & $(-1.30)$ & $(0.16)$ & (1.13) & $(2.17)^{* *}$ & & \\
\hline \multirow[t]{2}{*}{ GDP $_{\mathrm{Co}}$} & -0.34 & 0.10 & 4.03 & 1.57 & & \\
\hline & $(-1.24)$ & $(0.48)$ & $(3.87)^{* * *}$ & (1.13) & & \\
\hline \multirow[t]{2}{*}{ UnRate $_{\mathrm{Co}}$} & -0.70 & -0.78 & 1.80 & 1.25 & & \\
\hline & $(-3.63) * * *$ & $(-4.80) * * *$ & $(1.29)$ & $(0.77)$ & & \\
\hline \multirow[t]{2}{*}{ TrBal $_{\mathrm{Co}}$} & -0.52 & -0.58 & 1.39 & -0.67 & & \\
\hline & $(-2.08) * *$ & $(-2.92) * * *$ & $(1.09)$ & $(-1.00)$ & & \\
\hline \multirow[t]{2}{*}{ IntRate } & 0.16 & 0.57 & -0.81 & -0.23 & 1.08 & -0.99 \\
\hline & $(0.37)$ & $(1.71)^{*}$ & $(-4.25) * * *$ & $(-0.51)$ & $(18.82)^{* * *}$ & $(-1.83)^{*}$ \\
\hline \multirow[t]{2}{*}{ CPIEU } & 0.76 & 0.76 & 5.85 & 2.69 & 6.49 & 5.94 \\
\hline & $(2.70)^{* * *}$ & $(2.57)^{* *}$ & $(2.56)^{* *}$ & $(1.41)$ & $(3.19)^{* * *}$ & $(1.42)$ \\
\hline \multirow[t]{2}{*}{$\mathrm{GDP}_{\mathrm{EU}}$} & 0.57 & 0.51 & 3.71 & -0.32 & 1.31 & -0.61 \\
\hline & $(1.81)^{*}$ & $(1.83)^{*}$ & $(1.48)$ & $(-0.55)$ & $(0.64)$ & $(-1.16)$ \\
\hline \multirow[t]{2}{*}{ InProd $_{\mathrm{EU}}$} & 0.46 & 0.66 & 4.31 & 2.12 & 4.35 & 3.63 \\
\hline & $(2.00)^{* *}$ & $(2.57)^{* *}$ & $(2.60) * * *$ & $(1.59)$ & $(1.87)^{*}$ & $(1.89)^{*}$ \\
\hline \multirow[t]{2}{*}{ M3 } & -0.36 & -0.20 & -0.35 & 0.61 & 1.32 & 0.40 \\
\hline & $(-1.97)^{* *}$ & $(-1.22)$ & $(-1.11)$ & $(1.06)$ & $(0.95)$ & $(1.61)$ \\
\hline \multirow[t]{2}{*}{$\operatorname{TrBal}_{\mathrm{EU}}$} & 0.80 & 0.70 & 1.53 & 1.12 & 0.37 & 0.52 \\
\hline & $(2.99) * * *$ & $(2.81)^{* * *}$ & $(1.66)^{*}$ & $(1.28)$ & $(0.32)$ & $(0.24)$ \\
\hline \multirow[t]{2}{*}{ UnRateeu } & 0.52 & 0.32 & 1.92 & 2.62 & 2.79 & 2.78 \\
\hline & $(1.37)$ & $(1.13)$ & $(1.09)$ & $(2.16)^{* *}$ & $(1.39)$ & $(1.18)$ \\
\hline \multirow[t]{2}{*}{ CPIus } & 1.68 & 1.93 & 9.32 & 3.95 & 2.28 & 2.04 \\
\hline & $(5.22) * * *$ & $(6.00) * * *$ & $(5.99) * * *$ & $(2.17)^{* *}$ & $(0.81)$ & $(3.78) * * *$ \\
\hline \multirow[t]{2}{*}{ GDP $_{\text {US }}$} & 2.65 & 2.48 & 7.99 & 4.98 & 2.62 & 3.04 \\
\hline & $(7.23)^{* * *}$ & $(7.16)^{* * *}$ & $(2.97) * * *$ & $(4.66) * * *$ & $(2.25)^{* *}$ & $(3.35)^{* * *}$ \\
\hline \multirow[t]{2}{*}{ InProdus } & 1.43 & 1.79 & 1.06 & 4.67 & 2.77 & 4.44 \\
\hline & $(5.92)^{* * *}$ & $(7.19)^{* * *}$ & $(1.21)$ & $(1.54)$ & $(2.06)^{* *}$ & $(2.17)^{* *}$ \\
\hline \multirow[t]{2}{*}{ Lead } & 2.92 & 2.53 & 7.22 & 3.99 & 5.94 & 6.84 \\
\hline & $(10.16)^{* * *}$ & $(8.00)^{* * *}$ & $(4.65)^{* * *}$ & $(4.16) * * *$ & $(3.52)^{* * *}$ & $(2.83) * * *$ \\
\hline \multirow[t]{2}{*}{ TrBalus } & 1.16 & 0.72 & 1.36 & 5.72 & -1.73 & -1.02 \\
\hline & $(1.66)^{*}$ & $(1.10)$ & $(0.42)$ & $(5.30) * * *$ & $(-1.41)$ & $(-0.62)$ \\
\hline \multirow[t]{2}{*}{ UnRateus } & 0.78 & 0.26 & 6.67 & 1.98 & 3.95 & -1.42 \\
\hline & $(1.20)$ & $(0.43)$ & $(3.15)^{* * *}$ & $(0.76)$ & $(1.74)^{*}$ & $(-0.92)$ \\
\hline \multirow[t]{2}{*}{ US Open } & 2.16 & 2.02 & 4.78 & 4.03 & 4.43 & 3.89 \\
\hline & $(20.05)^{* * *}$ & $(18.29)^{* * *}$ & $(9.60) * * *$ & $(7.73) * * *$ & $(10.05)^{* * *}$ & $(10.34)^{* * *}$ \\
\hline Lags 1-6 & YES & YES & YES & YES & YES & YES \\
\hline Control Variables & YES & YES & YES & YES & YES & YES \\
\hline \multirow[t]{2}{*}{ Constant } & 71.11 & -63.27 & 73.32 & -91.50 & 80.01 & -87.77 \\
\hline & $(43.35)^{* * *}$ & $(-38.25)^{* * *}$ & $(12.27)^{* * *}$ & $(-12.83)^{* * *}$ & $(17.12)^{* * *}$ & $(-16.07)^{* * *}$ \\
\hline Adj-R ${ }^{2}$ & 0.77 & 0.77 & 0.81 & 0.82 & 0.55 & 0.55 \\
\hline $\begin{array}{l}\text { CPI refers to Consum } \\
\text { trade balance, interes } \\
\text { performance of the U } \\
\text { most important macr } \\
\text { to the US equity ma } \\
\text { parentheses. } *, * *, * *\end{array}$ & $\begin{array}{l}\text { ce Index and C } \\
\text { and industrial } \\
\text { nomy. All ann } \\
\text { omic announce } \\
\text { pening time. E } \\
\text { ote significance }\end{array}$ & $\begin{array}{l}\text { S Gross Domes } \\
\text { uction respecti } \\
\text { ments are dowı } \\
\text {. For Paris, all } \\
\text { quation is estir } \\
\text { e 10\%, } 5 \% \text { and }\end{array}$ & $\begin{array}{l}\text { roduct. UnRate } \\
\text { Leading indic } \\
\text { led from Bloon } \\
\text { roeconomic an } \\
\text { using OLS a } \\
\text { levels, respect }\end{array}$ & $\begin{array}{l}\text { Bal, IntRate and } \\
\text { (Lead) refers t } \\
\text { g. We used Blo } \\
\text { ccements are ma } \\
\text { Jewey-West sta }\end{array}$ & $\begin{array}{l}\text { rod refer to the } \\
\text { index that is } \\
\text { erg's relevance } \\
\text { efore market o } \\
\text { d errors are re }\end{array}$ & $\begin{array}{l}\text { mployment rate } \\
\text { ned to track the } \\
\text { ex to identify the } \\
\text { US open refers } \\
\text { d. T-statistics in }\end{array}$ \\
\hline
\end{tabular}




\begin{tabular}{|c|c|c|c|c|c|c|}
\hline \multicolumn{7}{|c|}{$\begin{array}{c}\text { Table } 6 \\
\text { Macroeconomic events: } \text { Spill over effects }\end{array}$} \\
\hline & \multicolumn{2}{|c|}{ Amsterdam } & \multicolumn{2}{|c|}{ London } & \multicolumn{2}{|c|}{ Paris } \\
\hline & Call & Put & Call & Put & Call & Put \\
\hline \multirow[t]{2}{*}{$\mathrm{CPI}_{\mathrm{Co}, \mathrm{Lon}}$} & 0.62 & 0.51 & & & 4.97 & 4.93 \\
\hline & $(2.56)^{* *}$ & $(2.41)^{* *}$ & & & $(2.14) * *$ & $(1.43)$ \\
\hline \multirow[t]{2}{*}{$\mathrm{GDP}_{\mathrm{Co}, \mathrm{Lon}}$} & 0.74 & 0.47 & & & 4.74 & 4.14 \\
\hline & $(2.44)^{* *}$ & $(1.80)^{*}$ & & & $(2.46) * *$ & $(2.01)^{* *}$ \\
\hline \multirow[t]{2}{*}{ UnRate $_{\mathrm{Co}, \text { Lon }}$} & 0.37 & 0.30 & & & 5.92 & 1.72 \\
\hline & $(1.62)$ & $(1.28)$ & & & (1.54) & $(0.81)$ \\
\hline \multirow{2}{*}{ TrBalCo, Lon $_{\text {}}$} & -0.02 & 0.04 & & & 1.52 & -0.78 \\
\hline & $(-0.06)$ & $(0.19)$ & & & $(0.90)$ & $(-3.60) * * *$ \\
\hline \multirow[t]{2}{*}{$\mathrm{CPI} \mathrm{Co}, \mathrm{Ams}_{\mathrm{A}}$} & & & -1.09 & 3.30 & -0.49 & -0.98 \\
\hline & & & $(-1.35)$ & $(1.53)$ & $(-0.84)$ & $(-2.08) * *$ \\
\hline \multirow[t]{2}{*}{$\mathrm{GDP}_{\mathrm{Co}, \mathrm{Ams}}$} & & & 0.53 & 0.88 & 0.08 & -0.87 \\
\hline & & & $(0.69)$ & $(0.57)$ & $(0.13)$ & $(-1.71)^{*}$ \\
\hline \multirow[t]{2}{*}{ UnRateco, Ams } & & & -0.93 & -0.20 & -1.73 & -0.61 \\
\hline & & & $(-1.84)^{*}$ & $(-0.44)$ & $(-1.18)$ & $(-1.08)$ \\
\hline \multirow[t]{2}{*}{ TrBalco, Ams } & & & -1.09 & -2.69 & -2.36 & -1.33 \\
\hline & & & $(-1.65)^{*}$ & $(-2.69) * * *$ & $(-1.55)$ & $(-2.00)^{* *}$ \\
\hline Lags 1-6 & YES & YES & YES & YES & YES & YES \\
\hline Control Variables & YES & YES & YES & YES & YES & YES \\
\hline Macro Dummies & YES & YES & YES & YES & YES & YES \\
\hline \multirow[t]{2}{*}{ Constant } & 70.81 & -62.90 & 73.50 & -94.23 & 82.20 & -98.33 \\
\hline & $(42.73) * * *$ & $(-38.83)^{* * *}$ & $(12.29)^{* * *}$ & $(-13.30)^{* * *}$ & $(17.71)^{* * *}$ & $(-17.70)^{* * *}$ \\
\hline Adjusted $\mathrm{R}^{2}$ & 0.77 & 0.77 & 0.81 & 0.82 & 0.55 & 0.55 \\
\hline \multicolumn{7}{|c|}{$\begin{array}{l}\text { CPI refers to Consumer Price Index and GDP is Gross Domestic Product. UnRate and TrBal refer to the unemployment rate } \\
\text { and trade balance respectively. The subscripts Lon and Ams refer to London and Amsterdam respectively. For Paris, all } \\
\text { country-specific macroeconomic announcements are made before the market opens. US open refers to the US equity market } \\
\text { opening time. Each equation is estimated using OLS and Newey-West standard errors are reported. T-statistics in parentheses. } \\
*, * *, * * * \text { denote significance at the } 10 \%, 5 \% \text { and } 1 \% \text { levels, respectively. }\end{array}$} \\
\hline
\end{tabular}


Figure 1

Intraday variation of standardized quoted bid-ask spread
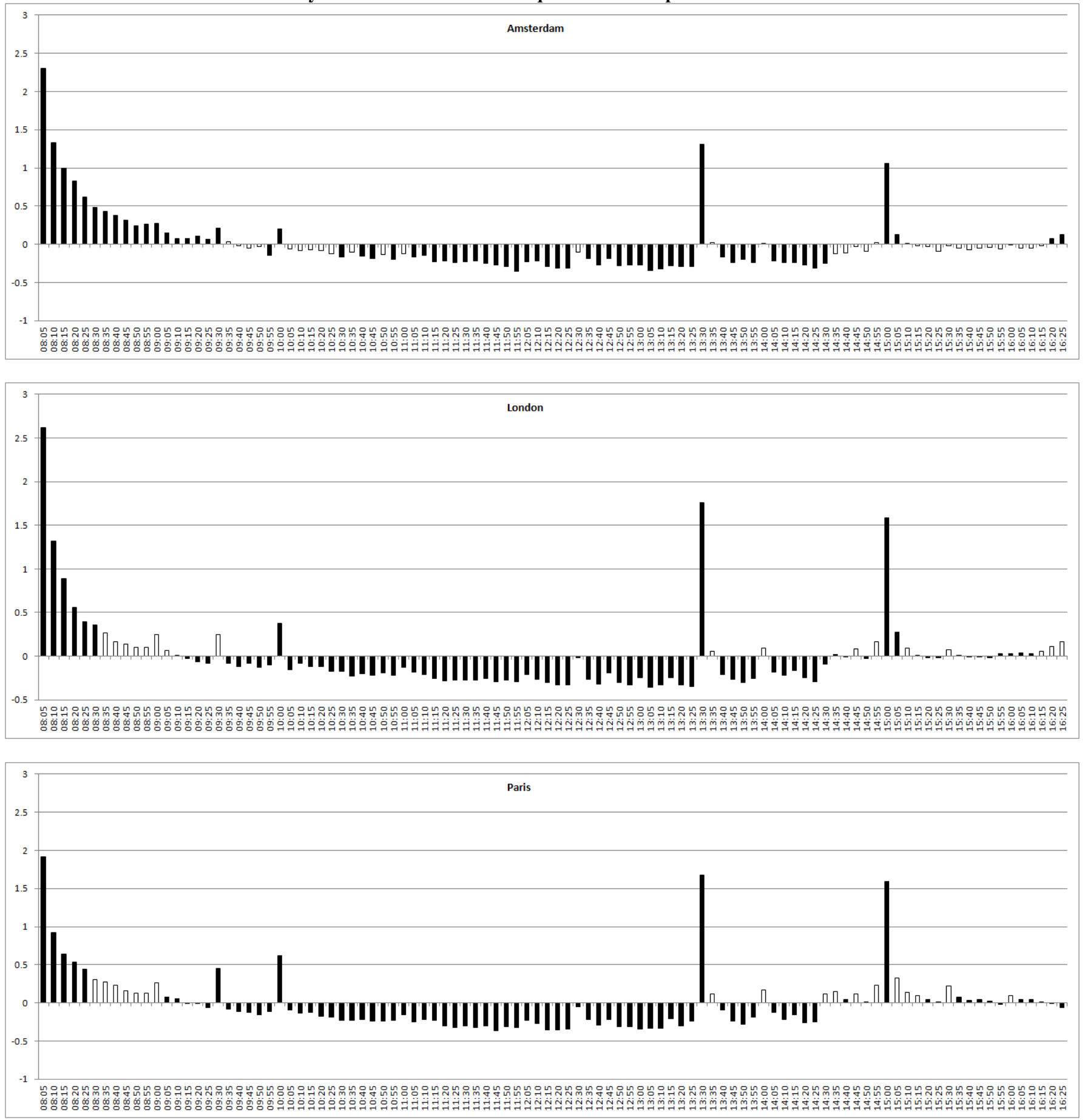

Spread refers to the percentage quoted bid-ask spread measured at 5-minute intervals. Each bar denotes the estimated coefficient of Equation (). In total there are 101-minute intervals during a day, however we drop the interval at the middle of the day (12:00-12:05) which is captured by the constant. When presenting the results, the coefficient for each intraday interval is the sum of the regression coefficient for that interval and the constant, therefore we drop the constant from the tables. Equation (6) is estimated with the Newey-West correction for autocorrelation and heteroscedasticity. Shaded bars denote a significant coefficient at the $5 \%$ level. 
Figure 2

Intraday variation of standardized depth
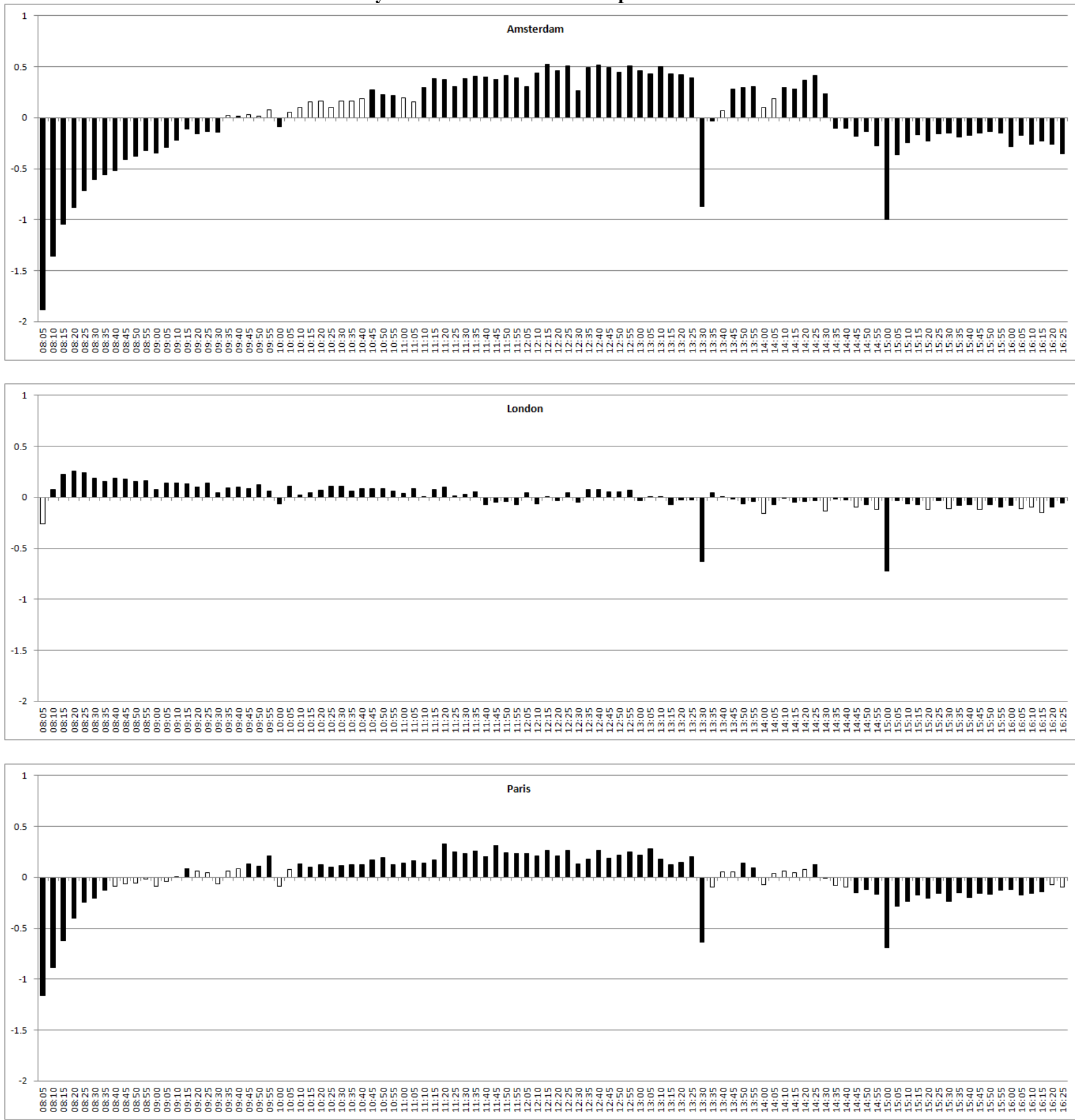

Depth refers to the sum of ask and bid volume, sampled at 5-minute intervals. Each bar denotes the estimated coefficient of Equation (6). In total there are 101-minute intervals during a day, however we drop the interval at the middle of the day (12:00-12:05) which is captured by the constant. When presenting the results, the coefficient for each intraday interval is the sum of the regression coefficient for that interval and the constant, therefore we drop the constant from the tables. Equation (7) is estimated using the Newey-West correction for autocorrelation and heteroscedasticity. Shaded bars denote a significant coefficient at the $5 \%$ level. 
Figure 3

Intraday variation of standardized volatility
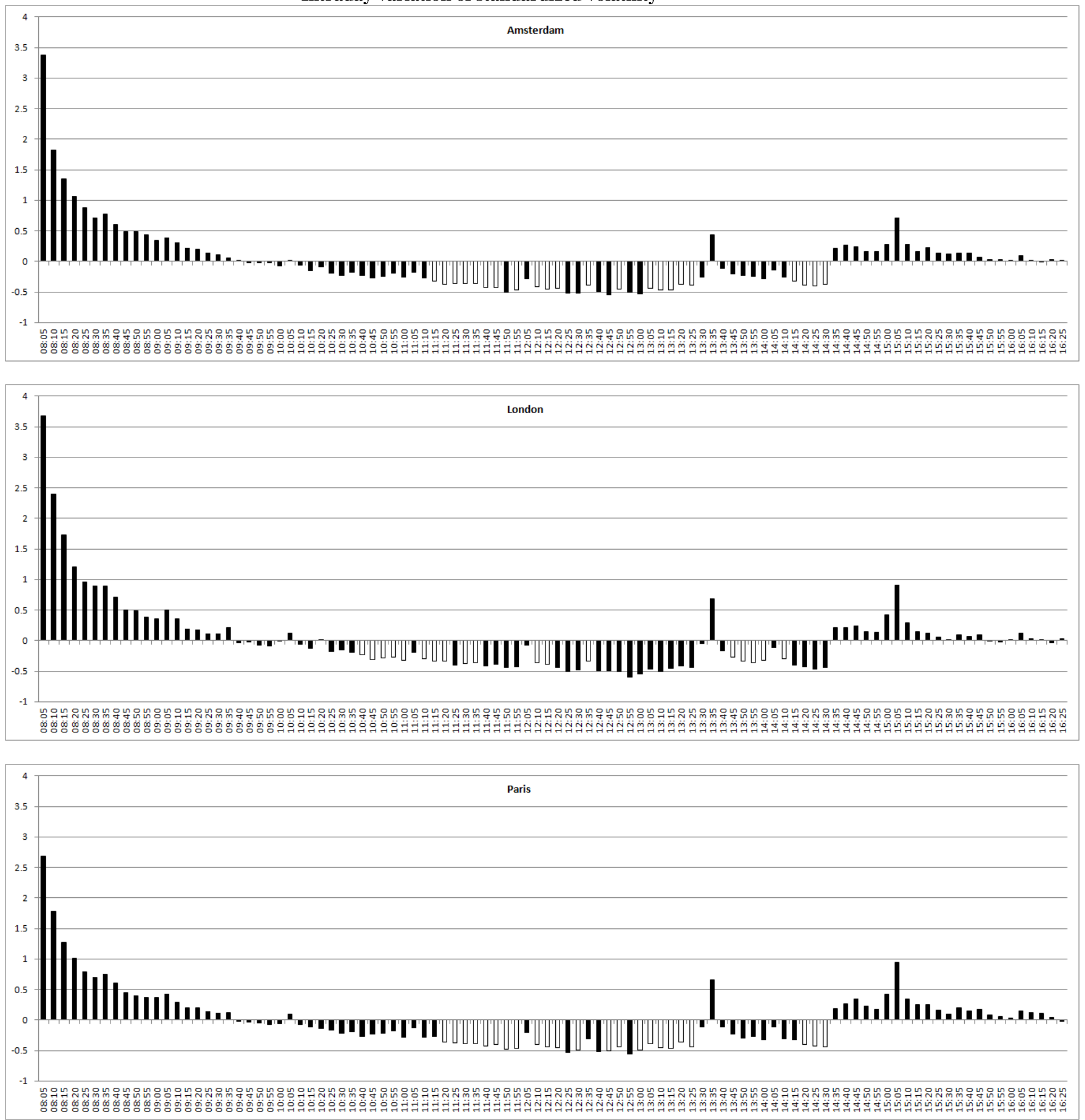

Volatility refers to the absolute value of 5-minute returns. Each bar denotes the estimated coefficient of Equation (7). In total there are 101minute intervals during a day, however we drop the interval at the middle of the day (12:00-12:05) which is captured by the constant. When presenting the results, the coefficient for each intraday interval is the sum of the regression coefficient for that interval and the constant, therefore we drop the constant from the tables. Equation (7) is estimated using the Newey-West correction for autocorrelation and heteroscedasticity. Shaded bars denote a significant coefficient at the $5 \%$ level. 
Figure 4

Shock duration

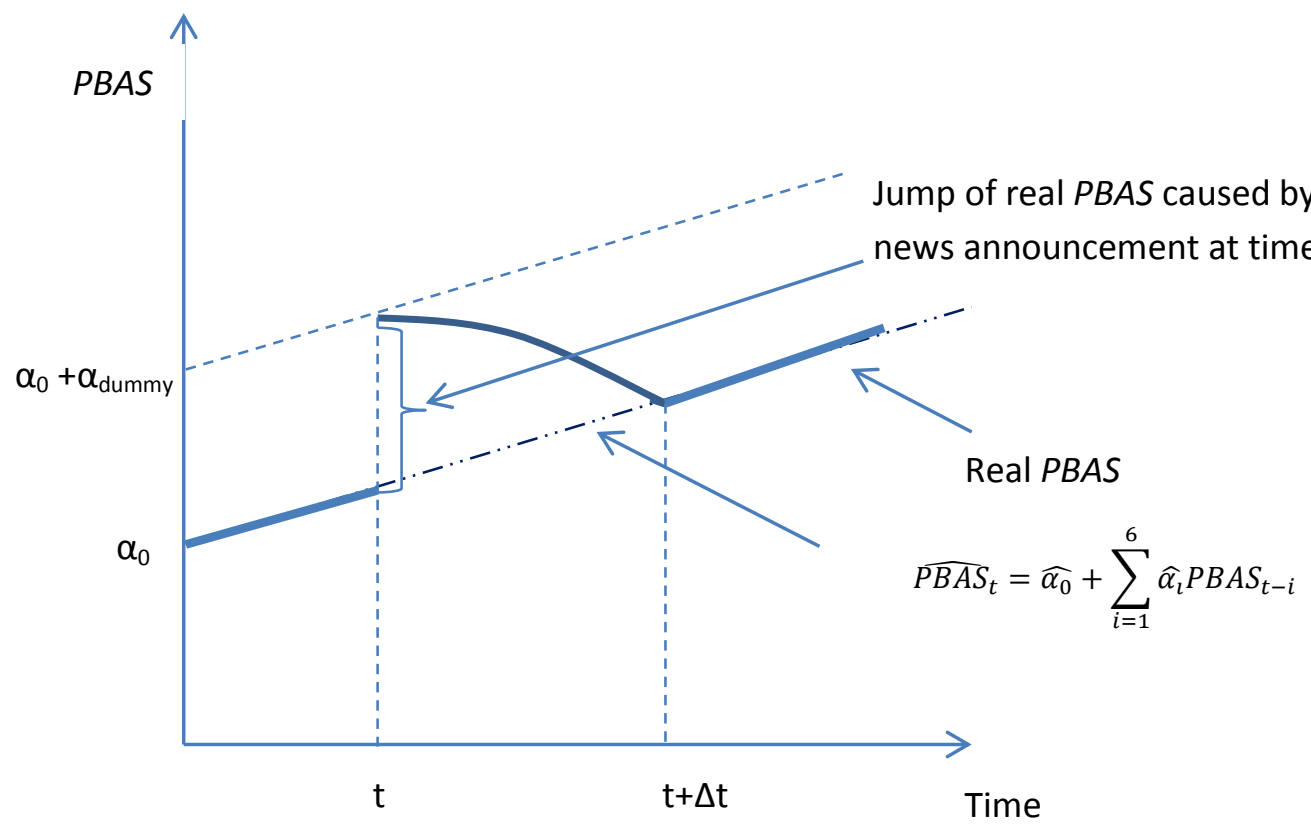

In this figure, we describe the process of comparing the real PBAS with the expected PBAS as it is predicted by an autoregressive equation after controlling for the macroeconomic shocks. A detailed explanation is provided in Section 5.1.2 
Figure 5

Shock duration: empirical results

Amsterdam Call

...... Country -----Euro —uS - - Us Open

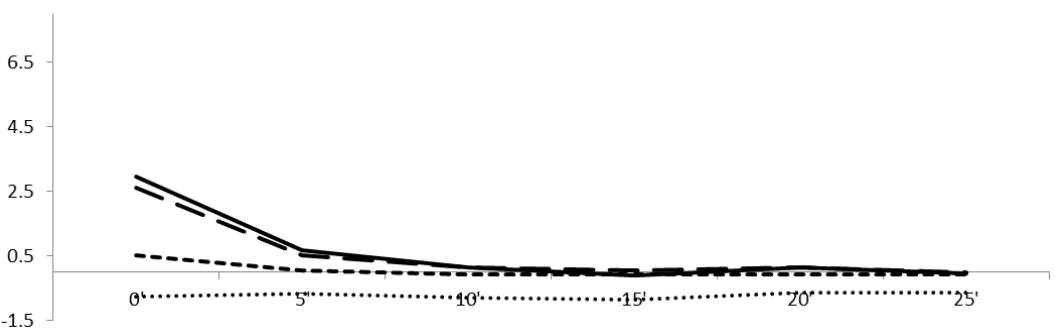

London Call

....... Country -----Euro —us - - us Open

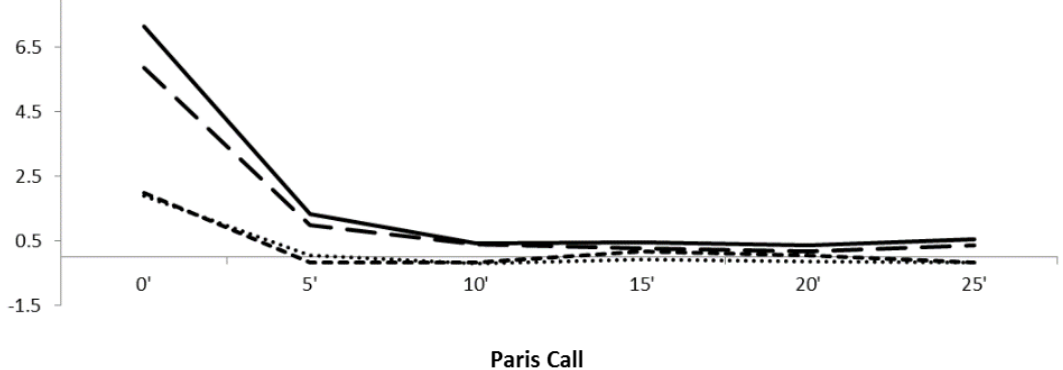

-...... country ----- Euro —us - us Open

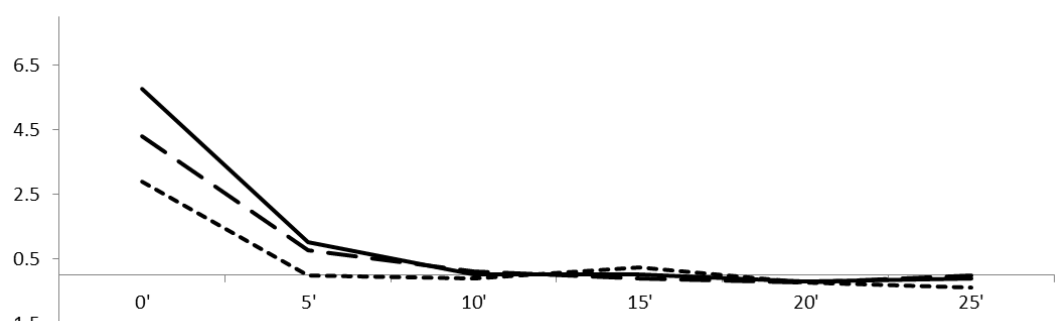

….... Country ----Euro - U US - - Us Open

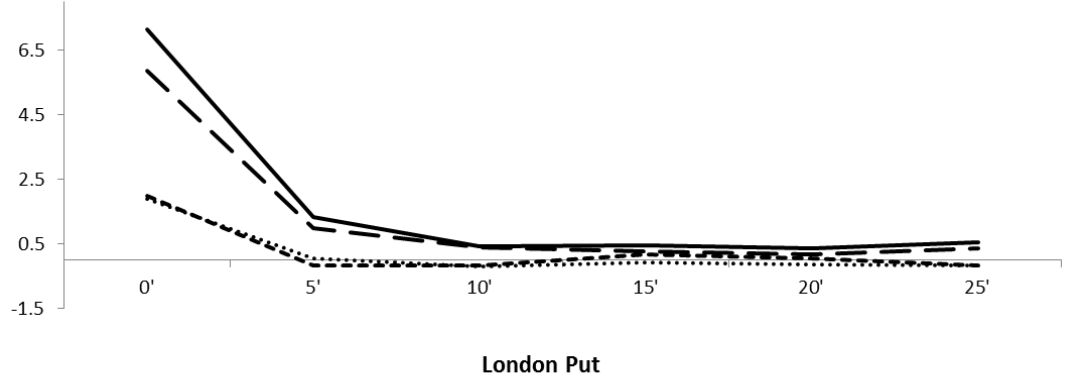

-...... Country ----. Euro - Us - - us Open

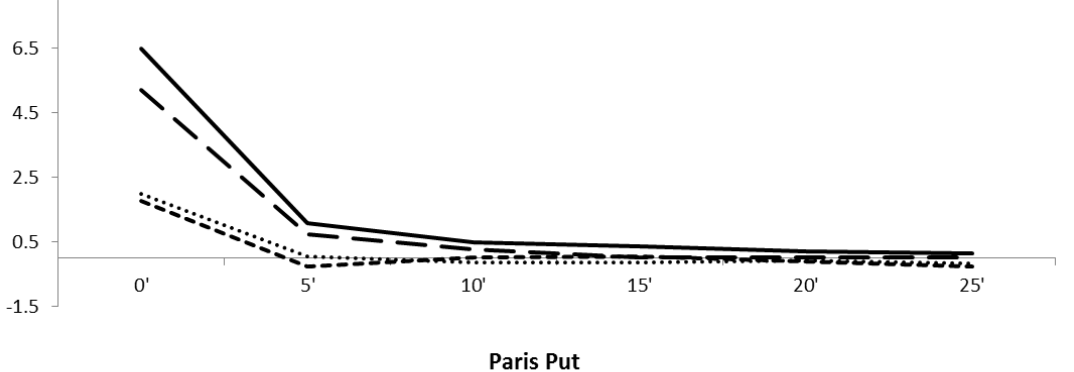

....... Country ----Euro —us - - us open

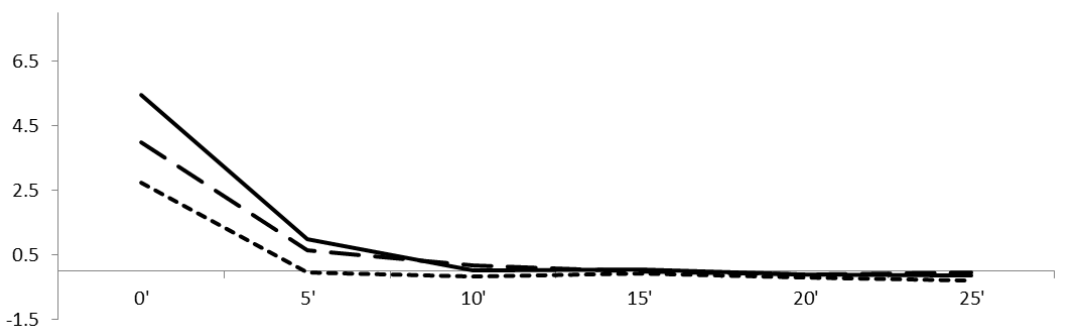

In this figure, we show how long it takes for the percentage bid-ask spread to revert back to its "normal" levels following macroeconomic shocks. The vertical axis refers to PBAS and the horizontal axis to time, measured in minutes. Country, Euro and US refer to country-, Euro- and US-specific macro announcements respectively. US open refers to the US equity market opening time. 


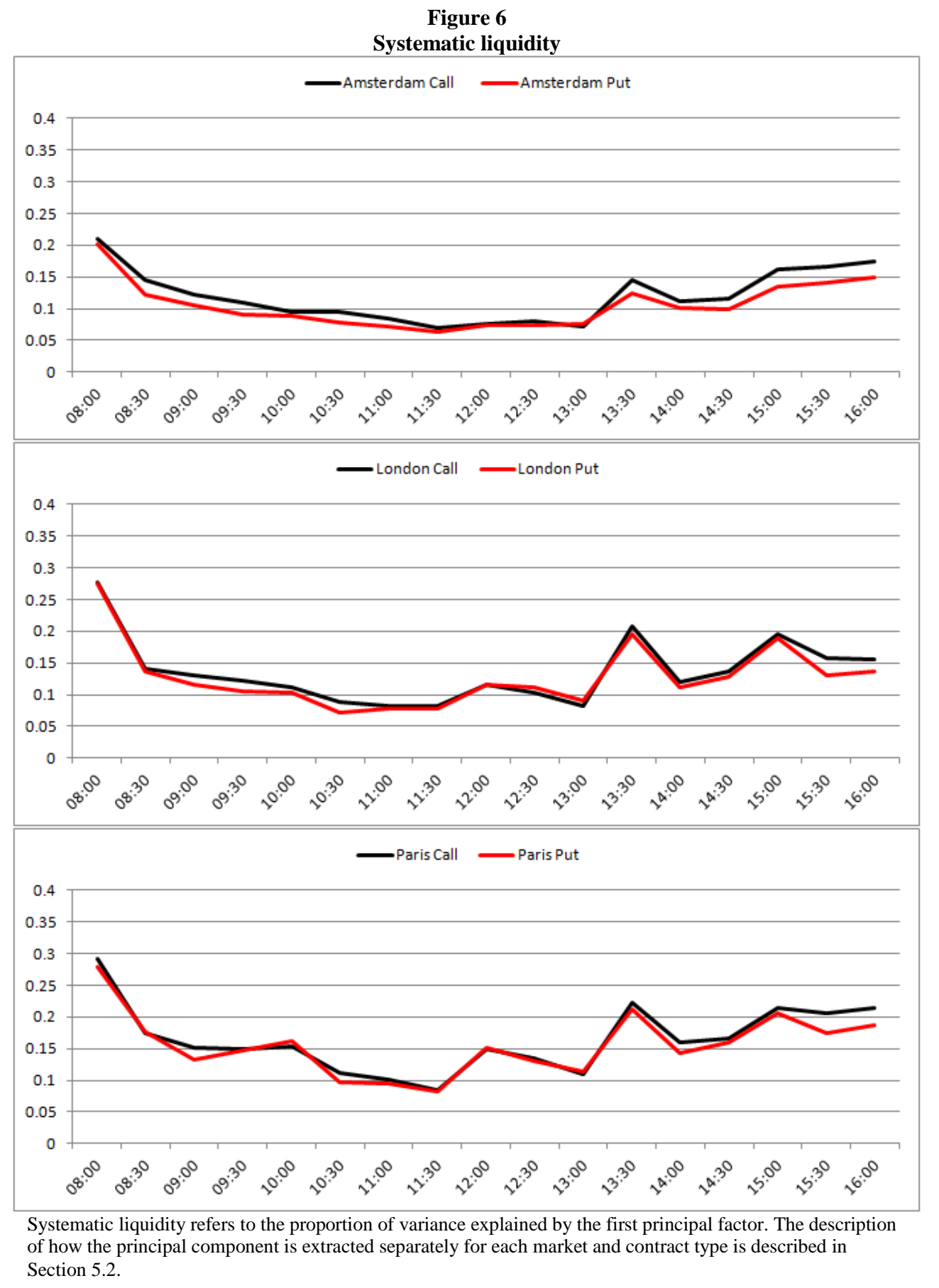

47 